\title{
LAS PENAS INFAMANTES EN LAS POSTRIMERÍAS DEL ANTIGUO RÉGIMEN FRANCÉS: TRATAMIENTO NORMATIVO Y DOCTRINAL*
}

\author{
Juan B. CAÑIZAREs-NavarRo \\ Profesor Permanente \\ Universidad CEU \\ Cardenal Herrera (Elche) \\ juan.canizares@uch.ceu.es
}

\begin{abstract}
RESUMEN
Durante casi dos siglos, el sistema punitivo francés de la Edad Contemporánea contó con una categoría de penas que recibió el nombre de «penas infamantes». Sin embargo, ese grupo de penas no fue creado por los legisladores contemporáneos, puesto que las fuentes jurídicas del Antiguo Régimen ya contenían esa denominación. La influencia de la tradición jurídica francesa en el Derecho codificado sobre esta materia invita a conocer el momento y la razón del origen de este tipo de penas. Para acabar de conocer las principales características de este conjunto de penas es necesario conocer qué eran las penas infamantes, qué penas fueron infamantes, cuáles fueron las principales características que diferenciaron estas penas de las demás y por ello qué papel desempeñaron esta clase de penas en el momento en el que surgieron. Para alcanzar dichos objetivos se analizan fuentes normativas -tanto legales como consuetudinarias - y doctrinales coetáneas en la medida en que eran las fuentes de creación y de interpretación del Derecho por antonomasia, y gracias a las fuentes doctrinales se podía conocer el contenido del Derecho romano y del Derecho canónico que estaba vigente en Francia en aquella época. Tras el análisis de dichas fuentes se observa que dicha categoría fue creada por la doctrina del Antiguo Régimen basando su configuración en una institución procedente del Derecho romano. Con su creación se dio origen a una categoría de castigos que tuvieron un importante protagonismo en el Antiguo Régimen tanto por la cantidad de penas que la formaron como por la cantidad de casos en los que se imponian.
\end{abstract}

Palabras clave: penas, infamia, honor, penas infamantes, Antiguo Régimen, Francia.

\section{ABSTRACT}

The french punitive system of the late modern period had a category of penalties named «infamous penalties» for almost two centuries. However, that category is

* El presente artículo ha sido llevado a cabo en el marco del proyecto «La influencia de la codificación francesa en la tradición penal española: su concreto alcance en la Parte General de los códigos decimonónicos», DER 2012-38469, proyecto financiado por el Ministerio de Economía y Competitividad español. 
not a new thing since it already appeared in the legal sources of the Ancien Régime. The fact that codified law regarding this subject have clearly been influenced by traditional French laws invites us to know when and why these penalties were created. In order to fully learn the features of such group of penalties we need to know what infamous penalties consisted of, which penalties were considered infamous, which features made them different from other penalties and therefore their role in their time. Such objectives can be obtained by studing normative sources, both legal and customary law, together with contemporary legal doctrine to the extent that those were the sources of origin and interpretation of law par excellence and it was thanks to such sources that we could get to learn the French Roman and canon law of that time. After looking into such sources we can see that such a category was created by the Ancien Régime legal doctrine based on a roman law institution. This new category led to the origin of a category of penalties of great importance in the Ancien Régime both because of amount of sentences that it comprised and because of the amount of cases involved.

Keywords: Penalties, Infamy, Honour, Infamous penalties, Ancien Régime, France.

\section{ZUSAMMENFASSUNG}

Während fast zwei Jahrbunderten beinhaltete das französische Strafsystem der Neuzeit eine Gruppe von Strafen, die man «entebrende Strafen» nannte. Jedoch wurden diese Strafen nicht erst durch die Gesetzgeber der Neuzeit erschaffen, sondern die juristischen Quellen des Gerichtssystems des Ancien Régime enthielten bereits Strafen unter dieser Bezeichnung. Der Einfluss der juristischen französischen Tradition auf das verfasste Gesetz läd dazu ein, den Ausgangspunkt und den Grund für diese Strafen zu untersuchen.. Um die charakteristischen Merkmale dieser Gruppe von Strafen kennenzulernen, muss man zunächst wissen, was und welche die «entehrenden Strafen» waren, welche charakteristischen Merkmale sie voneinander unterschieden und welche Rolle sie bei ibrer historischen Entstehung spielten. Um diese Ziele zu erreichen, werden sowobl Gesetzestexte als auch Gewohnheitsrechtsdokumente untersucht sofern sie die Quellen der Entstebung und der Auslegung des Rechts par excellence darstellen. Dank dieser Lebrquellen erschlie $\beta t$ sich der Inbalt des römischen Rechts und des Kirchenrechts, welches zu dieser Zeit in Frankreich galt. Nach dieser Untersuchung kann man beobachten, dass diese Strafkategorie von der Rechtsdoktrin des Ancien Régime auf der Grundlage des römischen Rechts geschaffen wurde. Diese Strafkategorie spielte eine bedeutende Rolle im Ancien Régime, sowobl hinsichtlich der Vielzahl der Strafarten, die sie umfasste als auch binsichtlich der großen Anzahl der Fälle, in der sie angewandt wurde.

Scblüsselwörter: Strafen, Entehrung, Ehre, entehrende Strafen, Ancien Régime, Frankreich.

SUMARIO: I. INTRODUCCIÓN.-II. LAS PENAS INFAMANTES EN LAS POSTRIMERÍAS DEL ANTIGUO RÉGIMEN FRANCÉS.-1. Concepto.-2. Penas consideradas infamantes.-3. Régimen jurídico de las penas consideradas infamantes.-A) Sujetos activos.-B) Sujetos pasivos.-C) Supuestos.D) Ejecución.-E) Efectos.-III. CONCLUSIONES.—IV. BIBLIOGRAFÍA. 


\section{INTRODUCCIÓN}

El interés por comparar el Derecho penal existente en España y Francia durante la Edad Contemporánea ha hecho optar por empezar conociendo el Derecho existente en el país galo, puesto que Francia fue el primer país de la Europa continental en el que se aprobó un Código Penal de corte liberal.

Dicho Código se promulgó en 1791. Los Códigos de 1791 y de 1795 fueron los primeros Códigos liberales de Derecho penal y de Derecho procesal penal, respectivamente, en aprobarse tras la caída del Antiguo Régimen ${ }^{1}$. Al consultar el contenido de los Códigos que se aprobaron en Francia se observa que en dicho país existió una categoría de penas llamada «penas infamantes»; concretamente, ese grupo de penas quedó recogido con ese nombre en los Códigos promulgados en 1795 y en 1810, por lo que la existencia de este grupo de penas duró hasta $1994^{2}$. Aunque se suele creer que el Derecho aprobado a partir del triunfo de la Revolución Francesa fue muy diferente al existente hasta entonces ${ }^{3}$, tal afirmación es discutible al menos por lo que respecta a las penas infamantes. Al intentar conocer los orígenes de este tipo de penas, la lectura de las fuentes del Derecho del Antiguo Régimen muestra la existencia de un grupo de penas

${ }^{1}$ A efectos político-jurídicos, el Antiguo Régimen francés es el periodo comprendido entre los siglos XIII y XVIII, por lo que este periodo existió durante la Baja Edad Media y la Edad Moderna. Se considera que el Antiguo Régimen surgió en el siglo XIII tras el despertar de la realeza, el desarrollo de las ciudades y el redescubrimiento del Derecho romano, provocando todo ello la construcción de un verdadero Estado de Justicia controlado por el rey y sus oficiales frente a la Justicia ejercida por otros poderes - sobre todo el señorial y el de la Iglesia-. Véase J. M. Carbasse, Histoire du droit pénal et de la justice criminelle, Paris, Presses Universitaires de France, 2000, pp. 78-79 y 123.

${ }^{2}$ El Código Penal de 1810 estuvo vigente desde el 1 de enero de 1811 hasta el 1 de marzo de 1994, día en el que entró en vigor el Código Penal actual (aunque dicho Código se promulgó el 22 de julio de 1992).

${ }_{3}$ Para Schnapper, con la caída del Antiguo Régimen se dio una reforma del Derecho penal. Sin embargo, Lascoumes, Poncela y, sobre todo, Martinage afirmaron que existió bastante continuismo. Martinage sostuvo que incluso el contenido del Código Penal de 1810 no supuso una completa ruptura en comparación con el contenido del Derecho Penal del Antiguo Régimen; por eso se dice que Napoleón y los redactores de dicho Código realizaron una transacción entre lo antiguo y lo nuevo. De hecho, dice que no se separó completamente de las penas provenientes del Antiguo Régimen aunque el Código de 1791 lo intentase en algún aspecto, en la medida en que no quiso dejar ningún margen de discrecionalidad para modular la pena en la sentencia condenatoria. Véase A. MASFERRER, «Continuismo, reformismo y ruptura en la codificación penal francesa. Contribución al estudio de una controversia historiográfica actual de alcance europeo», Anuario de Historia del Derecho Español, t. LXXIII, 2003, pp. 417-419. 
que recibió el mismo nombre. El adjetivo «infamante» procede del término «infamia», por lo que sería lógico pensar que la doctrina escogió dicho nombre porque la imposición y ejecución de dichas penas irrogara los mismos o parecidos efectos que la infamia. Teniendo en cuenta lo dicho, para poder investigar de forma exhaustiva cualquier materia relacionada con las penas infamantes de los Códigos franceses es necesario —o por lo menos recomendable- conocer las características principales de este tipo de castigos en el periodo inmediatamente anterior al de la etapa codificadora: las postrimerías del Antiguo Régimen.

El estudio de las penas existentes durante el Antiguo Régimen francés ofrece dificultades por la diversidad, la disparidad y la ausencia de una jerarquía clara de fuentes del Derecho que determinase las penas existentes. Eso justifica que en este periodo existiesen una gran cantidad y variedad de penas cuya imposición y ejecución dependió en numerosas ocasiones del arbitrio judicial ${ }^{4}$.

Por lo que se refiere a las penas infamantes como categoría de penas, a todo lo anterior habría que añadir que la historiografía no le ha dedicado la atención que se merecen en dicha época y lugar, pues solamente existen unas pocas publicaciones sobre concretas penas consideradas infamantes y sobre una institución estrechamente relacionada con estas penas: la infamia $^{5}$. Esta realidad justifica que se tenga que recurrir con frecuencia a las fuentes coetáneas para analizar esta materia.

${ }^{4}$ R. Anchel, Crimes et châtiments au XVIIIe siècle, Paris, Livrairie académique Perrin, 1933; CARBASSE, Histoire du droit pénal..., op. cit., p. 243, y A. LAIngui y A Lebigre, Histoire du droit pénal. I le droit pénal, Paris, Cujas, 1979-1980, pp. 10-13.

5 Sobre las penas infamantes francesas del Antiguo Régimen las publicaciones más destacables son las siguientes: J. M. CARBASSE, «Currant nudi: la répression de l'adultère dans le Midi médiéval (xIIe-Xve siècles)», en J. POumarèDE y J.-P. Royer (eds.), Droit, histoire et séxualité, Lille, Publications de l'Espace juridique, 1987, pp. 83-102; Y. CASTAN, «Exil ou prison en Languedoc au XviIIe siècle», en J.-G. PetiT, La prison, le bagne et l'bistoire, Genève-Paris, Médecine et Hygiène-Les Méridiens, 1984, pp. 57-68; J. M. MoegLIN, «Pénitence publique et amende honorable au Moyen Âge», Revue Historique, núm. 604, octubrediciembre de 1997, pp. 225-269, y P. C. TimbaL, «La confiscation dans le droit français des XIIIe et XIVe siècles», Revue historique de droit français et étranger, núm. 21, 1943, pp. 44-79. Por lo que respecta a la infamia, el trabajo más destacable es el de M. PORRET, «Atténuer le mal de l'infamie: le réformisme conservateur de Pierre-François Muyart de Vouglans», Crime, Histoire E Sociétés/Crime, History E Societies, vol. 4, núm. 2, 2000. Sin embargo, el conocimiento de la infamia ha sido abordado desde el Derecho romano hasta la etapa de la codificación española. Por lo que respecta al estudio de esta materia en el Derecho romano véanse F. CAMACHO DE LOS Ríos, La infamia en el Derecho Romano, Alicante (Generalitat Valenciana), Conselleria de Cultura, Educació i Ciència-Instituto de Cultura «Juan GilAlbert», 1997; A. FERNÁNDEZ DE BUJÁN, «Observaciones acerca de las nociones de ignominia e infamia en Derecho romano», en Homenaje a Juan Berchmans Vallet de Goytisolo, vol. IV, 
El conocimiento del origen de un grupo de penas que existió en Francia hasta finales del siglo xx y la escasez de bibliografía existente sobre las penas infamantes como conjunto de penas hacen necesario que se traten en un solo trabajo las siguientes cuestiones: el concepto de las penas infamantes, las penas que fueron consideradas infamantes y el régimen jurídico que tuvieron en común este tipo de castigos. Conociendo las características de las penas infamantes sobre estos aspectos se conocerán las características más importantes del grupo de penas que estamos tratando.

Las fuentes que se manejan para conocer dicha regulación son las fuentes normativas y las fuentes doctrinales de finales del Antiguo Régimen, además de las fuentes historiográficas existentes. Por fuentes normativas se entiende tanto la normativa legal como la normativa consuetudinaria. Como puede verse, no se presta atención al contenido de la jurisprudencia coetánea puesto que el presente trabajo se ocupa de conocer toda la teoría existente sobre las penas infamantes y no la aplicación de las mismas.

Para poder conocer el concepto de las penas infamantes en las postrimerías del Antiguo Régimen francés se analizan los elementos que compusieron el nombre de penas infamantes — pena, infamia y honor- a través del tratamiento proporcionado por las fuentes coetáneas e historiográficas que trataron sobre estas nociones, especialmente sobre las dos últimas. Con ello se podrá conocer el origen del nombre de «penas infamantes» y podrán conocerse las razones por las que se creó una categoría de penas con esta denominación.

El tratamiento de las penas infamantes hace necesario que se conozcan qué penas fueron infamantes. Para ello se recurre fundamentalmente a las fuentes coetáneas y gracias a ellas se pueden elaborar catálogos de penas infamantes en atención a su carácter infamante según dichas fuentes y en atención a las consecuencias de su imposición y ejecución. Tras esta labor podrá conocerse qué concretas penas fueron infamantes y la importancia cuantitativa y cualitativa de este tipo de sanciones penales en el Antiguo Régimen francés.

La última parte del trabajo se dedica al desarrollo del régimen jurídico de las penas infamantes del territorio y periodo que nos ocupan. El

Madrid, Junta de decanos de los Colegios Notariales de España, Consejo General del Notariado, 1989, pp. 313-341, y L. Pommeray, Études sur l'infamie en droit romain, Paris, Sirey, 1937. En cuanto al análisis de la infamia desde la etapa romana pasando por la época del Ius commune hasta la etapa de la codificación española, véase A. MASFERRER, La pena de infamia en el Derecho bistórico español. Contribución al estudio de la tradición penal europea en el marco del ius commune, Madrid, Dykinson, 2001. 
estudio del régimen jurídico de las penas consta del conocimiento de sus sujetos activos, sus sujetos pasivos, los supuestos en los que se imponía, la forma de ejecutar dicha pena y los efectos jurídicos que provocaban la imposición y ejecución de la misma. De todas estas materias, las que más información aportan sobre la naturaleza de las penas infamantes son la ejecución y los efectos producidos por esos castigos, por lo que el tratamiento de estas dos cuestiones es más detallado que el de los otros tres apartados. Esta información se basará en todas las fuentes coetáneas e historiográficas existentes, y gracias a los resultados obtenidos se pueden conocer con exactitud las razones por las que esas penas eran infamantes y se puede obtener de forma inductiva una sistematización de las penas infamantes ordenándolas jerárquicamente en atención a su gravedad.

\section{LAS PENAS INFAMANTES EN LAS POSTRIMERÍAS DEL ANTIGUO RÉGIMEN FRANCÉS}

\section{Concepto}

En el Derecho francés del Antiguo Régimen las fuentes de creación del Derecho nunca fijaron el sistema punitivo existente de forma completa y sistemática $^{6}$. Por tanto, podría decirse que en aquella época no hubo un sistema punitivo como tal.

En este contexto, la doctrina jurídica no solamente se dedicó a comentar e interpretar el contenido de las fuentes de creación del Derecho sobre las penas, sino que impulsó el desarrollo de la teoría penal ${ }^{7}$ basándose en todas las fuentes del Derecho existentes, facilitando con ello el conocimiento de todas las penas existentes en Francia y explicando su origen y finalidad.

${ }^{6}$ Las fuentes del Derecho penal del Antiguo Régimen francés fueron cinco: la legislación real, el Derecho romano, el Derecho canónico, la doctrina jurídica y la jurisprudencia. Además de estas fuentes habría que añadir la costumbre como fuente de creación del Derecho penal francés. En consecuencia, hubo cuatro fuentes de creación del Derecho penal francés - la legislación real, el Derecho romano, el Derecho canónico y la costumbre-, una fuente de interpretación del Derecho - la doctrina jurídica - y una fuente de aplicación del Derecho - la jurisprudencia-. Véase A. LAINGUI, «La sanction pénale dans le droit français du XVIIIT et XIXe siècle», en Recueil de la Société Jean Bodin pour l'bistoire comparative des institutions. La peine en Europe depuis le XviIIe siècle, vol. 57, Bruxelles, De Boeck Université, 1989, pp. 161-194, esp. p. 163.

7 Ibid., p. 172. 
Entre las fuentes del Derecho existentes durante el Antiguo Régimen, la doctrina jurídica es la única fuente en la que se encuentran definiciones de este tipo de penas.

La doctrina coincidió en definir la categoría de las penas infamantes como aquellos castigos impuestos y ejecutados por un órgano jurisdiccional que iban destinados exclusiva o al menos principalmente a menoscabar el honor de los condenados ${ }^{8}$. Por tanto, la doctrina mostró una opinión unánime sobre esa finalidad de las penas infamantes — disminuir exclusiva o principalmente el honor del condenado-.

Sin embargo, no todos los autores compartieron la opinión de que estas sanciones convertían en infames a los condenados a las mismas por llevar aparejada la infamia ${ }^{9}$. Por ello, no todos los autores franceses identificaron la categoría de las penas infamantes con las consecuencias y los efectos propios de la infamia.

Todos los autores de obras doctrinales coetáneas coincidieron en que las penas infamantes eran un tipo de penas y que tenían por finalidad única o principal mermar el honor del condenado a ellas, y la doctrina mayoritaria — por tanto, no de forma unánime- opinó que con la imposición y ejecución de este tipo de penas se pretendían dos cosas: menoscabar el honor de los condenados y convertirles en infames.

En el ámbito jurídico, la definición más aséptica de «pena» es aquella que la define como el castigo dado por un incumplimiento del Derecho. De ello se puede deducir que las penas infamantes eran un tipo de castigo dado por los órganos jurisdiccionales a determinadas vulneraciones del Derecho.

En los dos tipos de definiciones existentes sobre las penas infamantes se puede ver que éstas tenían por finalidad exclusiva o principal lesionar el honor del condenado. El honor siempre ha sido un bien inherente a todo ser humano y siempre fue objeto de tratamiento por el Derecho francés tanto para protegerlo ${ }^{10}$ como para menoscabarlo a través de la

${ }^{8}$ J. Domat, Les loix civiles dans leur ordre naturel, t. I, La Haye, Adrien Moetjens, 1703, p. 205; D. Jousse, Traité de la justice criminelle de France, t. I, Paris, Debure, 1771, p. 37; P.-F. MuYart DE Vouglans, Les loix criminelles de France dans leur ordre naturel dédiées au Roi, Paris, Mérigot, Crapart y Benoît Morin, 1780, pp. 74-75 y 79, y F. SERPILlon, Code criminel, ou commentaire sur l'Ordonnance de 1670, parte I y II, Lyon, Frères Perisse, 1767, pp. 676-677.

9 P.-F. Muyart de Vouglans, Les loix criminelles de France dans leur ordre naturel..., op. cit., p. 79.

${ }^{10}$ Los haberes de las personas que fueron objeto del Derecho francés fueron la vida, la libertad, los bienes y el honor. Véanse P.-F. MuYarT DE Vouglans, Les loix criminelles de 
imposición y ejecución de penas. El honor podría ser definido como la buena percepción que tienen los demás de una persona por la imagen que da de sí misma.

En la época de la que estamos tratando, el Derecho romano volvió a aplicarse en Francia ${ }^{11}$.

El nombre de «penas infamantes» fue acuñado y explicado por la doctrina coetánea. Con el fin de explicar el origen y la finalidad de todas las penas existentes en Francia, estos juristas crearon categorías de penas en atención a la finalidad única o principal perseguida con su imposición y ejecución, y cada categoría de pena recibió un nombre. Como la doctrina observó que había un conjunto de penas cuyo denominador común era que su imposición y ejecución pretendía lesionar única o fundamentalmente el honor de los condenados, aquellos juristas buscaron un adjetivo para calificar ese grupo de castigos. El nombre proporcionado a esas penas fue el de «penas infamantes» y el adjetivo «infamante» procede del término «infamia». La infamia era una institución jurídica recogida en el Derecho romano ${ }^{12}$, y la infamia romana siempre fue una consecuencia jurídica cuyos efectos menoscababan el honor de los condenados ${ }^{13}$.

France dans leur ordre naturel..., op. cit., pp. 50 y 52, y D. Jousse, Traité de la justice criminelle de France, op. cit., pp. 36-37.

Por lo que respecta a la protección del honor por parte del Derecho francés, el supuesto de hecho paradigmático fue el de las injurias. En relación con la injuria, la obra más completa cuyo ámbito cronológico es el Antiguo Régimen es la de F. Dareau, Traité des injures dans l'ordre judiciaire, ouvrage qui renferme particulièrement la jurisprudence du petit criminel, Paris, Prault, 1725.

${ }^{11}$ CARBASSE, Histoire du droit pénal..., op. cit., pp. 111-113. El trabajo más completo cuyo objeto es la recepción del Derecho romano en Francia es el escrito por A. Gouron, La science juridique française aux XIe et XIIe siècles: diffusion du droit de Justinien et influences canoniques jusqu'à Gratien, Milano, Giuffrè, 1978.

12 A. Masferrer, La pena de infamia en el Derecho bistórico español..., op. cit.; F. CAMACHO de los Ríos, La infamia en el Derecho Romano, op. cit., y A. Fernández de Buján, «Observaciones acerca de las nociones de ignominia e infamia...», op. cit.

${ }^{13} \mathrm{La}$ infamia romana siempre fue definida como una disminución de la buena fama cuyos efectos jurídicos menoscababan la dignidad civil del infame. La «buena fama» aparece definida en el Digesto gracias a Calístrato como «el estado de ilesa dignidad, comprobado por las leyes y las costumbres». La «buena fama» hacía referencia a la estimación civil, a la consideración y a la dignidad exterior que se tenía por ser un ciudadano romano con el disfrute de todos los privilegios públicos y privados que esta clase llevaba anejos. Véase A. MASFERRER, La pena de infamia en el Derecho histórico español..., op. cit., pp. 42 y 45-46. A lo largo de la historia, las causas por las que se sufrió la infamia fueron de tres tipos: 1) por ejercer determinados oficios o llevar a cabo determinadas actividades; 2) por observar conductas contrarias a la moral y a las buenas costumbres, y 3 ) por haber sufrido el pronunciamiento y la ejecución de determinadas penas. 
La infamia siguió existiendo en el Derecho francés del Antiguo Régimen a modo de consecuencia jurídica en determinados $\operatorname{casos}^{14}$, y la consecuencia de la irrogación de la infamia en esa época y lugar también tuvo efectos en el honor de los condenados ${ }^{15}$. Por tanto, la infamia fue una consecuencia jurídica existente en Francia por influencia del Derecho romano cuyo contenido estaba estrechamente vinculado con el honor. Con la noción de infamia, la doctrina encontró en un mismo término una institución que relacionaba el honor y la infamia, por lo que la utilización de la palabra «infamia» incluía en su contenido los dos elementos de las penas infamantes —el honor y la infamia — y servía a la perfección para referirse a este conjunto de penas.

Como en Francia existían penas cuya finalidad era única o principalmente deshonorar a los condenados a las mismas en virtud de la irrogación de infamia, esto motivó que la doctrina adoptase el calificativo de «infamante» para denominar la categoría compuesta por todos esos castigos.

Sin embargo, se indicó que hubo autores que consideraron que todas las penas infamantes no siempre llevaban aparejada la infamia. Así opinaba Muyart de Vouglans, quien diferenció las penas infamantes de derecho de las penas infamantes de hecho. Las primeras fueron definidas como aquellas que deshonoraban al condenado por la infamia en que se incurría

${ }_{14}$ A finales del Antiguo Régimen, en Francia un condenado se convertía en infame (de derecho) en tres casos:

1) A partir de la promulgación de la Ordenanza de 1670 ninguna pena pecuniaria acabaría irrogando la «infamia de derecho», por lo que este tipo de infamia se sufriría cuando alguien hubiera sido condenado a cualquier pena capital, corporal o aflictiva excepto las de muerte por decapitación, a la tortura y a la de azotes sous la custode, siempre que el supuesto de hecho fuera un acto infamante por naturaleza y que esa pena fuera proporcional al hecho que la motivó.

2) A partir de 1670, los condenados por los tribunales superiores a las penas pecuniarias de confiscación de bienes, multa en materia criminal y aumône en materia civil (aumône significa limosna, pero en este caso se trataba de una multa) serían infames por razón del pronunciamiento y ejecución de dichas penas.

3) El tercer caso en el que se incurriría en infamia de derecho era cuando alguien había sido condenado a penas a las que se unió la nota de infamia y que no podían calificarse como capitales, corporales, aflictivas o pecuniarias; se trataba de las penas que podrían denominarse infamantes de derecho.

Véanse G. Rousseaud de LA COMTE, Traité des matières criminelles suivant l'Ordonnance du mois d'Aôut de 1670, et les Édits, Déclarations du Roi, Arrêts et Réglemens intervenus jusqu'à présent, 5. ${ }^{a}$ ed., Paris, Théodore Le Gras, 1753, p. 4, y P.-F. MuYarT DE Vouglans, Les loix criminelles de France dans leur ordre naturel..., op. cit., pp. 74-75.

15 Aunque esta cuestión se va a tratar con más detenimiento más adelante, sí que interesa adelantar ahora que el pronunciamiento y la ejecución de la infamia producía efectos consistentes en limitar derechos externos del condenado, por lo que dichos efectos estaban muy relacionados con el honor del condenado. 
tras condena en juicio por alguna causa infamante. Por su parte, las segundas eran aquellas cuya imposición y ejecución simplemente mancillaban el honor de los condenados, haciendo disminuir con ello su estima; en este sentido, el propio jurista indicó que las penas infamantes de hecho «no son de naturaleza, ni infamantes, ni pecuniarias» ${ }^{16}$.

Muyart de Vouglans utilizó las denominaciones utilizadas desde época romana para diferenciar dos tipos de penas infamantes, pero se puede ver que dejó claro que la infamia propiamente dicha solamente existió en las penas infamantes de derecho. Por tanto, vista la definición que dio de las penas infamantes de derecho, Muyart de Vouglans opinó igual que el resto de la doctrina al decir que las únicas penas cuya consecuencia única o principal era deshonorar a través de la infamia eran las penas infamantes, entendiendo por tales las penas infamantes de derecho. Si otro grupo de penas fue denominado «infamantes de hecho» fue porque estos castigos solamente pretendían provocar la finalidad propia de las penas infamantes - el deshonor-, pero no la infamia.

Al observar los grupos de penas existentes se puede ver que el adjetivo «infamante» solamente apareció en el nombre de este conjunto de penas. Ello podría hacer pensar que las penas infamantes recibieron tal nombre porque eran los únicos castigos que infamaban a los condenados.

La infamia no se sufría solamente por parte de los condenados a las penas infamantes, puesto que los condenados a la mayoría de penas capitales, corporales y aflictivas también eran infamados ${ }^{17}$. A esto hay que añadir que la elección de los adjetivos «capitales», «corporales», «aflictivas» e «infamantes» para cada grupo de penas obedeció al objetivo principal o exclusivamente perseguido con la imposición y ejecución de las penas pertenecientes a una misma categoría; así lo demuestran las definiciones que se dieron de cada uno de estos tipos de penas ${ }^{18}$.

Como la mayoría de penas capitales, corporales y aflictivas llevaban aparejada la infamia, se puede decir que la designación del adjetivo «infa-

${ }^{16}$ P.-F. Muyart DE Vouglans, Les loix criminelles de France dans leur ordre naturel..., op. cit., pp. $74-75$ y 79 .

${ }_{17}$ D. Jousse, Traité de la justice criminelle de France, op. cit., pp. 36-37, y P.-F. MuYarT DE Vouglans, Les loix criminelles de France dans leur ordre naturel..., op. cit., pp. 74-75. Jousse indicó que la única pena aflictiva que no era infamante era la de tortura, mientras que Muyart De Vouglans indicó que no irrogaban infamia la pena de muerte por decapitación, la tortura y la pena de azotes sous la custode.

${ }_{18}$ Véanse D. Jousse, Traité de la justice criminelle de France, op. cit., pp. 36-37, y P.-F. MuyarT DE Vouglans, Les loix criminelles de France dans leur ordre naturel..., op. cit., pp. $53-54,59,68,74-75$ y 79 . 
mante» para hacer referencia a la categoría de las penas infamantes se debió a que las penas que formaron parte de este grupo tenían como única o principal finalidad el irrogar infamia a los condenados, mientras que las otras tres categorías de penas producían otros efectos con carácter principal. Todo esto permite afirmar que prácticamente todas las penas pronunciadas y ejecutadas por la jurisdicción penal eran infamantes porque siempre tenían por intención infamar a los condenados, y en las penas en las que mayor protagonismo ejercía la infamia como finalidad perseguida era en los castigos que formaron parte del grupo de las penas infamantes.

Gracias a todo lo dicho, se puede definir la categoría de las penas infamantes como aquel conjunto de sanciones penales cuya imposición y ejecución deshonoraba a los condenados, provocando además la infamia sobre los mismos cuando eran castigados a las penas infamantes de derecho.

\section{Penas consideradas infamantes}

Para conocer cuáles fueron las penas consideradas infamantes en el Antiguo Régimen es necesario recurrir a las obras doctrinales, puesto que la normativa del Antiguo Régimen no especificó las penas que llevaban aparejada la infamia; la única excepción a esta realidad fue un tipo de multa impuesta en materia criminal, puesto que se trataba de un castigo que llevaba aneja la infamia por prescripción normativa ${ }^{19}$.

De los dos elementos en los que se basaba el concepto de las penas infamantes —el honor y la infamia—, la noción de «honor» se ha caracterizado desde siempre por su abstracción, su mutabilidad y el carácter subjetivo respecto a la consideración de su importancia y extensión ${ }^{20}$. Sin embargo, la noción de la infamia francesa no ofreció dificultades de ese tipo, puesto que las fuentes del Derecho indicaron todos los requisitos que tenían que

19 F. MuyarT DE Vouglans, Les loix criminelles de France dans leur ordre naturel..., op. cit., p. 834.

Dicha multa estaba establecida en el art 7, título XXV, de la Ordenanza de 1670. La misma era impuesta como pena única en una sentencia de un órgano jurisdiccional de primera instancia. Sin embargo, en opinión de Loiseau y de Jousse, esta clase de multas solamente eran infamantes si eran pronunciadas junto con una pena que fuera infamante. Véase D. Jousse, Traité de la justice criminelle de France, op. cit., p. 77.

${ }^{20}$ Para conocer el papel del honor en el Derecho francés a lo largo de la historia véanse, sobre todo, B. BEIGNIER, L'honneur et le droit, Paris, LGDJ, 1995, y L. E. HaLKIN, «Pour une histoire de l'honneur», Annales. Économies, Sociétés, Civilisations, cuarto año, núm. 4, 1949, pp. 433-444. 
darse para que existiera infamia de derecho ${ }^{21}$; de esta forma, toda pena que objetivamente hubiese cumplido dichos requisitos sería considerada infamante (o como pena infamante de derecho según Muyart de Vouglans).

De todo lo dicho se puede deducir que resulta muy complicado - $\mathrm{O}$ al menos muy arriesgado- aventurarse a indicar con exactitud todas las penas infamantes de hecho que existieron, pero la determinación de las penas infamantes de derecho puede ser más exacta y detallada.

En la medida en que la imposición y ejecución de la mayoría de penas podía deshonorar al condenado, se llegó a decir que todas las penas eran infamantes ${ }^{22}$. A pesar de esto, ya vimos que Muyart de Vouglans diferenció las penas infamantes de derecho de las penas infamantes de hecho y detalló las penas que él consideraba infamantes de hecho ${ }^{23}$. Las penas que consideró expresamente como infamantes de hecho fueron las siguientes:

- La pena de admonition (amonestación o reprimenda verbal).

- La pena de abstención de lugares.

- La pena de interdicción temporal de oficios.

- La reparación de honor.

- Las défenses de reincidir (medidas que impedían que el condenado reincidiera).

- La injonction (conminación judicial).

- El plus amplement informé temporal, siempre que éste tuviera una duración de menos de un año y el condenado al mismo no tuviera que permanecer en prisión (especie de medida cautelar contra un imputado).

- Los intereses civiles.

- El hors de Cour (medida que impedía que el condenado al plus amplement informé temporal pudiera reclamar daños y perjuicios).

Por lo que respecta a las penas infamantes de derecho, las diferentes fuentes atribuyeron tal consideración a los castigos siguientes ${ }^{24}$ :

${ }^{21}$ Vid nota 14.

22 J. Domat, Les loix civiles dans leur ordre naturel, op. cit., p. 205; D. Jousse, Traité de la justice criminelle de France, op. cit., pp. 36-37 (salvo la tortura), y G. RoussEAUD DE LA Comte, Traité des matières criminelles suivant l'Ordonnance du mois d'Aôut de 1670..., op. cit., p. 4.

${ }^{23}$ F. Muyart de Vouglans, Les loix criminelles de France dans leur ordre naturel..., op. cit., pp. 78-81.

${ }^{24}$ La bibliografía que se ha tenido en cuenta para elaborar el listado que sigue es la más destacable y la más influyente de la época en la materia que nos ocupa, por lo que se advierte que no se citan a todos los autores que se han pronunciado sobre esta cuestión. Tenien- 
- El blâme ${ }^{25}$.

- La multa en materia criminal ${ }^{26}$.

- La amende bonorable in figuris (un tipo de disculpa verbal en público por el ilícito cometido) ${ }^{27}$.

- Los azotes recibidos en público, a lo que a veces se añadía una marca en el condenado ${ }^{28}$.

- El bannissement temporal (un tipo de destierro temporal) ${ }^{29}$.

- El bannissement perpetuo (un tipo de destierro perpetuo) ${ }^{30}$.

do en cuenta lo dicho, consideramos que es suficiente con citar la bibliografía que aparece en las notas al pie correspondientes, pues esas obras son suficientes para conocer el estado de opinión imperante en ese periodo. Aunque se ha pretendido elaborar un elenco de penas infamantes de derecho lo más completo posible, los problemas que estamos viendo y veremos que ofrecía el sistema de fuentes de aquella época podrían ocasionar que algún autor diferente a los consultados hubiera considerado infamante de derecho alguna pena que no hemos encontrado en los demás autores; de hecho, vamos a tener ocasión de apreciar que una misma pena era considerada por unos como infamante de derecho y por otros como infamante de hecho. Podría ocurrir que faltara por nombrar algún castigo, pero lo que se puede afirmar con rotundidad es que se ha intentado proporcionar un listado lo más exhaustivo posible con base en la bibliografía más completa a la que se ha podido acceder, y por eso es poco probable que se haya dejado de mencionar alguno de estos castigos.

${ }_{25}$ J. Domat, Les loix civiles dans leur ordre naturel, op. cit., p. 205; D. Jousse, Traité de la justice criminelle de France, op. cit., p. 69; F. MuYART DE Vouglans, Les loix criminelles de France dans leur ordre naturel..., op. cit., p. 77; F. SERPILLON, Code criminel, ou commentaire sur l'Ordonnance de 1670, op. cit., p. 681, y J.-A. Soulatges, Traité des crimes, t. I, Toulouse, Antoine Birosse, 1762, sobre todo p. 177.

26 A. BRuneau, Observations et maximes sur les matières criminelles, Paris, Guillaume Cavelier, 1715, p. 292 (siempre que esa multa haya sido confirmada por fallo en segunda instancia); D. Jousse, Traité de la justice criminelle de France, op. cit., pp. 69-73; G. RoussEAUD DE LA COMTE, Traité des matières criminelles suivant l'Ordonnance du mois d'Aôut de 1670..., op. cit., pp. 4 y 448, y J.-A. Soulatges, Traité des crimes, op. cit., sobre todo p. 177. En este sentido, más de un autor indicó que los tribunales podían condenar a esta pena diciendo expresamente «sans que l'amende puisse porter note d'infamie» («sin que la multa pueda llevar nota de infamia»).

${ }^{27}$ C. Loiseau, Cinq livres du droit des offices, Châteaudun, 1610, p. 158; F. SERPILLON, Code criminel, ou commentaire sur l'Ordonnance de 1670, op. cit., p. 679, y J.-A. SouLATGES, Traité des crimes, op. cit., sobre todo p. 177. Sobre la amende honorable véase J.-M. Moeglin, «Pénitence publique et amende honorable au Moyen Âge», op. cit.

28 A. Bruneau, Observations et maximes sur les matières criminelles, op. cit., p. 145; A. LOISEL, Institutes coutumières ou manuel de plusieurs et diverses règles, sentences et proverbes, tant anciens que modernes, du Droit Coutumier et plus ordinaire de la France, Paris, Henry Le Gras, 1656, pp. 340-341, y J.-A. Soulatges, Traité des crimes, op. cit., sobre todo p. 177.

${ }^{29}$ C. LoIseau, Cinq livres du droit des offices, op. cit., p. 158; F. MuYarT DE Vouglans, Les loix criminelles de France dans leur ordre naturel..., op. cit., p. 72, y J.-A. SOULATGES, Traité des crimes, op. cit., sobre todo p. 177. Sobre el bannissement en el Antiguo Régimen véase Y. CASTAN, «Exil ou prison en Languedoc au XVIIIe siècle», op. cit.

30 C. Loiseau, Cinq livres du droit des offices, op. cit., p. 158; F. Muyart DE Vouglans, Les loix criminelles de France dans leur ordre naturel..., op. cit., y J.-A. Soulatges, Traité des 
- La aumône en materia civil (multa en materia civil) ${ }^{31}$.

- La destitución, privación o interdicción perpetua de los oficios ${ }^{32}$.

- El colgamiento por las axilas ${ }^{33}$.

- El carcan (un tipo de exposición pública) ${ }^{34}$.

- La pena de azotes ejecutada en privado - normalmente en dependencias de las prisiones- y sin marcar al condenado ${ }^{35}$.

- La degradación de nobleza ${ }^{36}$.

- Las galeras perpetuas ${ }^{37}$.

- Las galeras temporales ${ }^{38}$.

- La condena de la memoria ${ }^{39}$.

- El plus amplement informé indefinido y el temporal, siempre que éste tuviera una duración mínima de un año y el condenado a la misma tuviera que permanecer en prisión ${ }^{40}$.

- La muerte física ${ }^{41}$.

- La muerte civil ${ }^{42}$.

- Presenciar la ejecución de la pena de muerte por potence (la potence era una de las formas de ejecución de la pena de muerte para los plebeyos) ${ }^{43}$.

- La privación de beneficios ${ }^{44}$.

crimes, op. cit., sobre todo p. 177. Al igual que para la pena de bannissement temporal véase Y. CASTAN, «Exil ou prison en Languedoc au XVIIIe siècle», op. cit.

${ }^{31}$ G. Rousseaud DE LA Comte, Traité des matières criminelles suivant l'Ordonnance $d u$ mois d'Aôut de 1670..., op. cit., pp. 447-448, y J.-A. Soulatges, Traité des crimes, op. cit., sobre todo p. 177.

32 Sobre todo en D. Jousse, Traité de la justice criminelle de France, op. cit., pp. 73-74, y F. MuYarT DE Vouglans, Les loix criminelles de France dans leur ordre naturel..., op. cit., pp. 77-78.

33 D. Jousse, Traité de la justice criminelle de France, op. cit., p. 60, y F. MUYART DE Vouglans, Les loix criminelles de France dans leur ordre naturel..., op. cit., p. 65.

34 J.-A. Soulatges, Traité des crimes, op. cit., sobre todo p. 177.

35 A. Bruneau, Observations et maximes sur les matières criminelles, op. cit., p. 145.

36 F. Muyart DE Vouglans, Les loix criminelles de France dans leur ordre naturel..., op. cit., p. 77.

37 J.-A. Soulatges, Traité des crimes, op. cit., sobre todo p. 177.

38 Ibid.

39 F. Muyart DE Vouglans, Les loix criminelles de France dans leur ordre naturel..., op. cit., p. 76.

${ }^{40}$ Ibid., pp. 78-79.

${ }^{41} \mathrm{~J}$.-A. Soulatges, Traité des crimes, op. cit., sobre todo p. 177.

42 F. MuYart De Vouglans, Les loix criminelles de France dans leur ordre naturel.., op. cit., p. 75.

${ }_{43}$ D. Jousse, Traité de la justice criminelle de France, op. cit., p. 69.

44 Ibid., pp. 74-75. 
- La privación de privilegios ${ }^{45}$.

- El desalojo de un bien inmueble ${ }^{46}$.

- La supresión, lacerado o quema de escritos ${ }^{47}$.

- La confiscación de bienes ${ }^{48}$.

- Ser llevado por las calles con un sombrero de paja puesto ${ }^{49}$.

La determinación de la naturaleza infamante de las penas fue dispar e incluso contradictoria entre los diferentes autores. Esa falta de unanimidad de opiniones tuvo como principal causa la ausencia de unas fuentes normativas aplicadas en todo el territorio francés que tuvieran un contenido completo, claro y unitario en el que fijasen el sistema punitivo existente y su contenido, ya que dichas fuentes del Derecho no detallaron todas las penas existentes ni su naturaleza ${ }^{50}$.

A falta de fuentes normativas claras y completas, los juristas mostraron pareceres distintos sobre la determinación del carácter infamante de las penas debido a los diferentes argumentos sobre los que basaron sus opiniones. Aunque no todos los autores motivaron su parecer, los que sí lo hicieron lo fundamentaron en todas o en algunas de las siguientes razones: 1) en la calificación realizada por las fuentes de creación del Derecho existentes sobre las penas —en aquellas fuentes que así lo hicieron-; 2) en el procedimiento a seguir en la causa judicial que podía dar lugar a la imposición y ejecución de penas infamantes; 3 ) en la jurisprudencia existente; 4) en la forma de ejecución de las penas, y 5) en los efectos producidos por

${ }^{45}$ Ibid., p. 75.

46 Ibid.

${ }^{47}$ Ibid., p. 76.

${ }^{48}$ F. MuYaRT DE Vouglans, Les loix criminelles de France dans leur ordre naturel..., op. cit., pp. 75 y 81. Sobre la confiscación de bienes véase, sobre todo, P.-C. TIMBAL, «La confiscation dans le droit français des XIIIe et XIVe siècles», op. cit.

${ }^{49}$ D. Jousse, Traité de la justice criminelle de France, op. cit., p. 68.

50 Dentro de este periodo, la Ordenanza de 1670 fue la fuente normativa que mayor exhaustividad y claridad proporcionó para el conocimiento del sistema punitivo existente. Aunque dicha Ordenanza tuviese por contenido principal el Derecho procesal penal en vez del Derecho penal sustantivo, el contenido del art. 13 del título XXV estableció una escala de penas en la que se especificaron tanto las penas existentes como la prelación existente entre ellas en atención a su gravedad. Sin embargo, esta regulación ha sido calificada como incompleta porque puede apreciarse que ese precepto no recogió todas las penas existentes. Véanse A. Laingui y A. Lebigre, Histoire du droit pénal. I le droit pénal, op. cit., p. 125, y A. LaINGUI, «La sanction pénale dans le droit français du XVIIIe et XIXe siècle», op. cit., p. 172. En consecuencia, habrá que esperar a la aprobación del Código Penal de 1791 para que una norma establezca todas las penas existentes, y no será hasta 1795 cuando la promulgación del «Código de los delitos y de las penas» suponga una fijación de todas las sanciones penales existentes, clasificándolas de forma sistemática. 
su imposición y ejecución. Cuantos más argumentos motivaban el carácter infamante de una pena, mayor cantidad de autores los alegaron para mostrarse partidarios de la consideración de esa misma pena como infamante, y con ello mayor consenso existió en la doctrina sobre el carácter infamante de esa pena en comparación con otras ${ }^{51}$.

En atención a los elencos expuestos anteriormente, puede verse que en aquella época hubo entre treinta y cuarenta penas consideradas infamantes $^{52}$; de entre ellas, unas veinticinco fueron infamantes de derecho y una

${ }^{51}$ Si se tiene en cuenta la cantidad de penas que se consideraron infamantes, la enumeración de los argumentos proporcionados por cada autor para motivar el carácter infamante de todas estas penas merecería un estudio cuya extensión excede los límites de este trabajo. Aunque solamente sirva a modo de ejemplo, si el blâme fue la pena que mayor consenso logró en su consideración como pena infamante ello se debió a que a lo largo de la historia existió un mayor número de argumentos que motivaron su carácter infamante y dichos argumentos nunca llegaron a contradecirse entre sí, por lo que todos los autores utilizaron los mismos argumentos a favor de su carácter infamante y de ahí la aceptación generalizada de la consideración del blâme como castigo infamante. Sin embargo, la multa en materia criminal no tuvo tan amplia consideración como pena infamante como la que tuvo el blâme porque las fuentes de creación del Derecho no siempre consideraron que aquélla fuera una pena infamante, por lo que el carácter infamante de esta pena en la normativa y en la jurisprudencia llegó a ser dispar y con ello el consenso existente sobre su carácter infamante fue menor que con el blâme. Véanse, sobre todo, J. DOMAT, Les loix civiles dans leur ordre naturel, op. cit., p. 205; D. Jousse, Traité de la justice criminelle de France, op. cit., p. 69; F. MuYART DE Vouglans, Les loix criminelles de France dans leur ordre naturel..., op. cit., pp. 77 y 84, y F. SERPILLON, Code criminel, ou commentaire sur l'Ordonnance de 1670, op. cit., pp. 1091-1092.

52 Como puede verse, se ha preferido dar un número aproximado y no un número exacto de las penas infamantes existentes. La razón de ello se debe a las dificultades existentes a la hora de computar convenientemente el número de castigos existentes, puesto que el cómputo se puede llevar a cabo al menos de las siguientes formas: a) contando cada una de las penas independientemente de que su nombre sea compartido con otra (por ejemplo, el bannissement perpetuo y el bannissement temporal, teniendo en cuenta que la segunda fue considerada infamante de derecho por más autores que la primera); b) contando como un solo castigo aquellas penas que compartiesen el mismo nombre (en el ejemplo puesto anteriormente, que el bannissement perpetuo y el temporal computasen como una sola pena, porque la mayor diferencia entre una y otra estribaba en la duración del castigo), o c) atendiendo solamente a la naturaleza de las penas (en el ejemplo indicado, contar como pertenecientes a un mismo grupo todas aquellas penas que supusieran la imposibilidad de vivir en un concreto lugar, por lo que en este caso podrían computarse como una misma pena el bannissement perpetuo, el temporal, lo que se llamó el exilio, la abstención de lugares, etc.). Al menos en nuestro objeto de estudio, la elección de un método u otro tiene más relevancia de la que parece, ya que el carácter infamante en ocasiones dependía de la forma de ejecución o de la duración del cumplimiento de la pena. En cualquier caso, el objeto de este trabajo no es dar un número exacto de las penas infamantes que existieron, sino dar a conocer qué concretas penas eran infamantes, qué peso tuvo este tipo de penas en el conjunto del sistema punitivo en el que se encuadraron y, por último, conocer la razón por la que fueron infamantes, por lo que podemos conformarnos con dar un número aproximado sobre esta cuestión. 
decena fueron calificadas como infamantes de hecho - pudiendo algunas de éstas considerarse infamantes de derecho dependiendo de la duración y de la forma de ejecución de las mismas-.

En el sistema punitivo francés del Antiguo Régimen, el número de penas existente está comprendido entre las cincuenta y las sesenta ${ }^{53}$. Sobre este medio centenar de penas, ya hemos apuntado que unas veinticinco eran infamantes de derecho y al menos una decena fueron infamantes de hecho.

Por otra parte, Jousse enumeró todas las penas que seguían utilizándose en Francia en la segunda mitad del siglo XVIII ${ }^{54}$. En su catálogo de penas había entre veinte y treinta castigos ${ }^{55}$. De esas penas, si se tiene en cuenta el parecer del mismo autor, solamente tres de ellas podían considerarse infamantes de derecho ${ }^{56}$, mientras que, atendiendo a los elencos proporcionados anteriormente que reflejan la opinión imperante, se puede observar que más de la mitad de esas penas eran infamantes - y dentro de éstas, prácticamente todas eran infamantes de derecho- ${ }^{57}$.

${ }^{53}$ Las dos obras doctrinales más importantes de aquella época -D. Jousse, Traité de la justice criminelle de France, op. cit., y F. MUYART DE VOUGLANS, Les loix criminelles de France dans leur ordre naturel..., op. cit.- apuntaron todas las penas existentes en el Antiguo Régimen francés. Si se suman todos los castigos apuntados entre estas dos obras se puede comprobar que el número de castigos existentes gira en torno a esa cantidad.

${ }_{54}$ D. Jousse, Traité de la justice criminelle de France, op. cit., pp. 38-39. En la bibliografía que hemos consultado, Jousse es el único autor que elabora una lista de este tipo.

${ }_{55}$ Partiendo de que el elenco proporcionado por Jousse sea correcto y completo, si se cuentan todas las penas escritas separadamente por Jousse la lista que proporciona está compuesta por veintitrés castigos. Sin embargo, a modo de ejemplo Jousse redactó de forma separada la exposición pública de dos formas diferentes, la pena de muerte ejecutada de cinco formas diferentes o las tres formas diferentes de llevar a cabo mutilaciones, mientras que no utilizó el mismo método atendiendo a la diferente forma de ejecución o duración de una misma pena, por ejemplo en los dos tipos de reclusión que existían; de haber seguido el mismo criterio enumerador que el que utilizó para las exposiciones públicas - cosa recomendable si se tiene en cuenta que el carácter infamante en ocasiones dependía de la forma de ejecución o de la duración del cumplimiento de la pena-, su listado podría llegar a estar compuesto por veintiocho castigos. Por ello, una vez más nos encontramos ante el problema del cómputo de las penas, pero ante la falta de necesidad de contar con exactitud cuántas penas fueron redactadas por Jousse, en nuestro caso es suficiente con dar la cifra aproximada que se ha proporcionado.

56 Se trata de las penas de amende honorable, blâme y ser paseado por las calles con un sombrero de paja puesto. Jousse nunca especificó en su obra el carácter infamante de hecho de una pena, por lo que no se puede conocer con exactitud qué castigos eran infamantes de hecho según su opinión. Véase D. Jousse, Traité de la justice criminelle de France, op. cit., pp. 68-76.

57 En el listado elaborado por Jousse las penas que no eran infamantes según el estado de opinión imperante eran las que siguen: los dos tipos de tortura que indica, el pilori (una forma de exposición del condenado pero no en lugares abiertos al público), las tres mane- 
Si se compara la proporción de penas infamantes existentes en ambos periodos —antes de mediados del siglo XVIII y desde mediados del siglo XVIII-, las penas infamantes ganaron presencia en comparación con otras clases de castigos. Esto podría explicarse debido a la dulcificación que se dio en el contenido y, sobre todo, en la aplicación del Derecho penal hacia finales del Antiguo Régimen ${ }^{58}$; en este sentido, a menor número de penas atroces existentes - que casi siempre eran penas capitales, corporales o aflictivas - ${ }^{59} \mathrm{y}$ a parecido número de penas infamantes ${ }^{60}$, mayor proporción de penas infamantes en el sistema punitivo.

En cualquier caso, ha de tenerse en cuenta que toda pena capital y aflictiva también era infamante ${ }^{61}$.

Todo esto permite observar que con el paso del tiempo el número de penas vigentes en Francia se redujo considerablemente, pero esa reducción no supuso una menor presencia de las penas infamantes entre los castigos existentes en este periodo, sino que podría decirse que ocurrió lo contrario. Partiendo de la idea de que prácticamente toda pena podía llegar a deshonorar —en cuyo caso se podría decir que las penas infamantes de hecho fueron los castigos predominantes en el Antiguo Régimen-, no hay duda de que las penas infamantes de derecho siempre estuvieron muy presentes en el Derecho francés del Antiguo Régimen, ocupando un lugar de gran importancia cuantitativa y cualitativa en cuanto a su presencia e imposición.

ras de mutilar que recoge, la reclusión indefinida y la temporal, y el arrastramiento del cadáver de determinados condenados.

58 Sobre esta evolución véanse, sobre todo, A. LAINGUI, «Lois, juges et docteurs dans l'ancien droit pénal», Cabiers de philosophie politique et juridique, Caen, 1988, pp. 73-89, y L.-E. Halkin, «La cruauté des supplices de l'Ancien Régime», Revue historique de droit français et étranger, Paris, Sirey, 1937, pp. 131-144. Aunque el título de esta publicación pueda llevar a engaño, Halkin sostuvo que lo que a veces aparentaba ser una ejecución atroz en realidad lo que se estaba haciendo era aplicar prácticas que suavizaban el rigor originario de esa pena.

59 En el texto principal se indicó que el número de penas existentes y aplicables durante el Antiguo Régimen bajó hasta la mitad (desde las cincuenta-sesenta hasta las veinte-treinta si nos fiamos de los datos aportados por Jousse).

${ }^{60}$ Siguiendo las cantidades que hemos apuntado en el texto principal $-\mathrm{y}$ siempre que el listado proporcionado por Jousse fuese completo-, el número de penas infamantes de derecho existentes y en uso durante todo el Antiguo Régimen se movió en torno a la veintena.

${ }^{61}$ Véase nota 17 y su texto principal. 


\section{Régimen jurídico de las penas consideradas infamantes}

El estudio del régimen jurídico de una pena consta del conocimiento de sus sujetos activos ${ }^{62}$, sus sujetos pasivos ${ }^{63}$, los supuestos en los que se imponía ${ }^{64}$, la forma de ejecutar dicha pena ${ }^{65}$ y los efectos jurídicos que provocaban la imposición y ejecución de la misma ${ }^{66}$.

El concepto de las penas infamantes gira en torno a dos nociones: la de honor y la de infamia. Si se tiene en cuenta la definición del honor ${ }^{67}$, el deshonor causado con una pena sería provocado sobre todo a través de la ejecución de la misma. Por su parte, teniendo en cuenta el significado de la infamia ${ }^{68}$, la misma se materializaría en los efectos jurídicos provocados por la imposición y ejecución de una pena.

Ya hemos podido ver la gran cantidad de penas infamantes que existieron. Ello impide que el presente trabajo pueda abordar el tratamiento del régimen jurídico completo de todas ellas, puesto que el estudio del régimen jurídico de cada una de ellas podría ser objeto individualizado de un artículo propio, y el análisis del régimen jurídico de todas las penas infamantes necesitaría ser abordado en una monografía. Estas son las razones por las que el estudio de la ejecución y los efectos de las penas infamantes va a ser más exhaustivo que el de los sujetos activos, los sujetos pasivos y los supuestos de hecho.

\section{A) Sujetos activos}

Los únicos sujetos activos de las penas infamantes eran los órganos jurisdiccionales —independientemente del número de miembros que los compusieran- ${ }^{69}$.

\footnotetext{
${ }^{62}$ Por «sujetos activos» se entiende aquellos sujetos legitimados para poder imponer penas infamantes.

${ }^{63} \mathrm{La}$ expresión «sujetos pasivos» es utilizada para referirse a los sujetos contra los que se podían imponer penas infamantes.

${ }^{64} \mathrm{La}$ palabra «supuestos» hace referencia a las acciones previstas por el Derecho que podían provocar la imposición de una pena infamante.

${ }^{65}$ El vocablo «ejecución» indica el proceso seguido para hacer cumplir la imposición de una pena infamante.

${ }^{66}$ Los «efectos» son las consecuencias jurídicas que sufría un condenado a una pena infamante.

${ }^{67} \mathrm{Al}$ principio de este trabajo definimos el honor como la buena percepción que tienen los demás de una persona por la imagen que ésta da de sí misma.

${ }^{68}$ Véanse notas 13 y 14 y su texto principal.

${ }^{69}$ Durante el Antiguo Régimen, algunas poblaciones crearon una institución llamada
} 
Con carácter general, el único tipo de jueces que podía imponer este tipo de penas sin ninguna limitación era el colectivo formado por los jueces reales ${ }^{70}$. Los jueces de los señoríos también eran competentes para imponer todo tipo de penas infamantes en el ámbito laico ${ }^{71}$. Sin embargo, estos juzgadores no podían imponer la pena de privación de oficio a oficiales reales ${ }^{72}$. Por último, los jueces que nunca podían imponer castigos infamantes en el ámbito civil eran los jueces eclesiásticos ${ }^{73}$.

\section{B) Sujetos pasivos}

Una vez indicados los tipos de órganos jurisdiccionales que podían imponer penas infamantes, los destinatarios de este tipo de castigos podían ser personas físicas o personas jurídicas ${ }^{74}$.

Entre las personas físicas, en principio, toda persona sufriría la imposición y ejecución de las penas infamantes independientemente de su condición social —noble o plebeya, laica o religiosa—, sexo o edad ${ }^{75}$. Sin embargo, tanto los nobles como las mujeres se vieron beneficiados en rela-

«árbitros» o «amigables componedores». A modo de ejemplo, las Costumbres de Bouillon recogieron esta institución, y en las mismas establecieron que los fallos dictados por estas instituciones no llevaban infamia (art. II del capítulo VII de las Costumbres de Bouillon). Véase C. Bourdot De Richebourg, Nouveau Coutumier Général, ou Corps des Coutumes générales et particulières de France, et des Provinces connues sous le nom des Gaules, parte II, t. II, Paris, Michel Brunet, 1724, p. 850.

Para conocer la administración de justicia en Francia durante el Antiguo Régimen -especialmente desde el siglo XV— véase, sobre todo, A. LAINGU y A. LebigRE, Histoire du droit pénal. II la procédure criminelle, Paris, Cujas, 1979-1980, pp. 75-77.

${ }_{70}$ D. Jousse, Traité de la justice criminelle de France, op. cit., pp. 68-76. Así puede deducirse de todos los sujetos activos que estaban legitimados para imponer y ejecutar penas infamantes según Jousse.

${ }^{71}$ Un ejemplo de esta regulación se puede encontrar en el contenido de las Costumbres Generales del Bailiaje de Bassigny. En las mismas puede leerse que el señor de la más alta instancia jurisdiccional tenía jurisdicción sobre los ilícitos penales que llevaban toda pena con «notas de infamia» (art. 1 del título 1. ${ }^{\circ}$ de las Costumbres Generales del Bailiaje de Bassigny). Véase C. Bourdot De Richebourg, Nouveau Coutumier Général, ou Corps des Coutumes générales et particulières de France..., op. cit., p. 1140.

${ }_{72}$ D. Jousse, Traité de la justice criminelle de France, op. cit., p. 73.

73 La pena de privación de beneficio era una pena considerada infamante que normalmente se imponía por jueces eclesiásticos. Sin embargo, los jueces reales también podían imponerla. Por tanto, los sujetos activos más frecuentes en esta pena eran los jueces eclesiásticos. Véase D. Jousse, Traité de la justice criminelle de France, op. cit., p. 41.

${ }_{74}$ Entendemos por «personas jurídicas» aquellas entidades pluripersonales que eran titulares de derechos y obligaciones en cuanto tales.

75 D. Jousse, Traité de la justice criminelle de France, op. cit., p. 41. 
ción con la imposición de determinadas penas infamantes. En el caso de los nobles, la pena de carcan casi nunca era impuesta a los mismos ${ }^{76}$. Por lo que respectaba a las mujeres, en el Parlamento de París no se condenaba a las mujeres a sufrir la pena de bannissement fuera del reino ${ }^{77}$. En otros casos, la condición de mujer tenía consecuencias opuestas a las que acabamos de indicar, puesto que por el hecho de ser mujeres esto las hacía destinatarias de imposición de penas infamantes ${ }^{78}$.

Por lo demás, los hombres eran sujetos pasivos de las diferentes penas infamantes, incluidos los varones impúberes ${ }^{79}$. En cuanto a los adultos, tanto los civiles como las autoridades podían ser condenados a este tipo de castigos en caso de cometer las conductas ilícitas que llevaban aparejadas esas penas ${ }^{80}$.

Las personas físicas no eran el único tipo de sujeto pasivo contra quienes podía infligirse penas infamantes, puesto que las personas jurídicas también podían ser objeto de ejecución de dichas penas ${ }^{81}$.

\section{C) Supuestos}

$\mathrm{Al}$ igual que ocurría en relación con los sujetos pasivos a los que se les podían imponer penas infamantes, las conductas ilícitas castigadas con penas infamantes podían haber sido realizadas por personas físicas o por personas jurídicas.

Cuando los sujetos pasivos eran personas físicas, en aquella época la mayor parte de conductas ilícitas que acababan siendo juzgadas tenían por consecuencia jurídica imponer una pena infamante. Por tanto, lo normal era que la mayoría de causas criminales fueran merecedoras de pena infamante ${ }^{82}$.

76 Ibid.

77 Ibid.

78 El ejemplo más claro de esto es el que se dio en los supuestos que provocaban la condena a ser paseado por las calles con un sombrero de paja, porque en este caso los sujetos pasivos de estas penas eran fundamentalmente mujeres. Véase D. Jousse, Traité de la justice criminelle de France, op. cit., p. 68.

79 Ibid., pp. 69-76.

80 Ibid.

81 Eso le ocurría a las ciudades o a las comunidades que llevaban a cabo conductas subsumibles en supuestos de hecho que llevan aparejada la pena de privación de privilegios. Véase D. Jousse, Traité de la justice criminelle de France, op. cit., p. 75.

82 Ello tenía lugar por la imposición de penas de multa en materia criminal. Como en la mayoría de procesos penales se imponían multas de este tipo, y estas multas irrogaban infa- 
Partiendo de esa norma general en relación con las personas físicas, las conductas que normalmente eran merecedoras de imponer una pena infamante eran las siguientes: 1) las relativas a la regencia o dirección de actividades relacionadas con la prostitución; 2) comportamientos basados en malos hábitos que podían ser peligrosos para el orden social ${ }^{83}$;3) aquellas conductas tipificadas cuya realización suponía la imposición de pena de muerte para los púberes, y 4) la redacción, impresión, venta o reparto de escritos sediciosos ${ }^{84}$.

En los casos en los que los sujetos pasivos de penas infamantes eran personas jurídicas, las conductas ilícitas tipificadas eran la rebelión, la violencia o cualquier otro tipo de conducta criminosa cometida por cualquier población en cuanto tal -independientemente de que posteriormente se juzgase a los verdaderos culpables y a los cómplices de esa conducta- ${ }^{85}$.

\section{D) Ejecución}

Si se tiene en cuenta la naturaleza de las dos nociones sobre las que se fundamentaban las penas infamantes —el honor y la infamia, aunque sobre todo en la primera-, la ejecución influiría de manera decisiva en la irrogación de deshonor y/o infamia.

\section{Ejecución infamante en público}

Conviene señalar que por ejecución en público se entiende toda ejecución en lugares en los que podían congregarse más personas que las que formaban parte de la causa judicial en la que se había pronunciado la pena - los miembros del órgano jurisdiccional y las partes-. Las penas infamantes ejecutadas en público fueron las siguientes:

mia, sobre todo en opinión de la jurisprudencia, en la gran mayoría de causas criminales habría algún tipo de pena infamante. Como puede verse, esta afirmación confirma el aserto que hemos hecho en este trabajo en relación con la frecuencia de supuestos de hecho que eran castigados con penas infamantes. Véase D. Jousse, Traité de la justice criminelle de France, op. cit., pp. 69-73

${ }_{83}$ En este sentido, un edicto de Francisco I en 1536 establecía la imposición de la infamia y de otras penas para los borrachos incorregibles. Véase Edicto de Francisco I en 1536, en F. LORRY, Code pénal, ou recueil des principales ordonnances, édits et déclarations, sur les crimes et délits, 2." ed., Paris, Desaint et Saillant, 1755, p. 246.

${ }^{84}$ D. Jousse, Traité de la justice criminelle de France, op. cit., p. 76.

${ }^{85}$ Ibid., pp. 64 y 75. 
- La amende bonorable in figuris ${ }^{86}$.

- El blâme ${ }^{87}$.

- Los azotes recibidos en público, a lo que a veces se añadía una marca en el condenado ${ }^{88}$.

- La muerte física ${ }^{89}$.

- El colgamiento por las axilas ${ }^{90}$.

- El carcan ${ }^{91}$.

- Presenciar la ejecución de la pena de muerte por potence ${ }^{92}$.

${ }^{86}$ La amende honorable in figuris se ejecutaba de la siguiente forma: el condenado comparecía solamente con el tronco cubierto, descalzo, llevando una antorcha en la mano y a veces incluso llevando una cuerda atada al cuello, y se arrodillaba en la puerta de uno o más de un edificio emblemático. Véanse D. Jousse, Traité de la justice criminelle de France, op. cit., p. 63, y P.-F. MuYART De Vouglans, Les loix criminelles de France dans leur ordre naturel..., op. cit., p. 67. Para conocer más detalles sobre la ejecución de este castigo véase J.-M. Moeglin, «Pénitence publique et amende honorable au Moyen Âge», op. cit.

${ }^{87}$ El blâme se ejecutaba con la cara descubierta y arrodillado ante los miembros del órgano jurisdiccional en sede judicial. Véanse D. Jousse, Traité de la justice criminelle de France, op. cit., p. 69, y P.-F. MuYarT De Vouglans, Les loix criminelles de France dans leur ordre naturel..., op. cit., p. 77.

${ }^{88}$ Este tipo de azotes eran realizados por los verdugos en cruces de calles y plazas públicas. Si además de haber sido azotado algún condenado era marcado, se marcaba una flor de lis o las iniciales atendiendo a la pena principal a la que había sido condenado - GAL (de la pena de galeras) - o atendiendo al tipo de ilícito que había cometido para ser condenado a esa pena - $\mathrm{V}$ de vol (robo en francés) - , y en el Antiguo Régimen la marca solía hacerse en el hombro. Véanse D. Jousse, Traité de la justice criminelle de France, op. cit., pp. 58-59, y P.-F. MuYart De Vouglans, Les loix criminelles de France dans leur ordre naturel..., op. cit., pp. 63-64.

89 A pesar de haber existido muchas formas diferentes de ejecutar la pena de muerte, parece que la misma se ejecutaba casi siempre en lugares públicos, destacando sobre todas las demás formas de ejecución la de descuartizamiento por cuatro caballos. Véanse D. JousSE, Traité de la justice criminelle de France, op. cit., pp. 42-46, y P.-F. Muyart De Vouglans, Les loix criminelles de France dans leur ordre naturel..., op. cit., pp. 53-59.

${ }_{90}$ Este castigo se ejecutaba colgando al impúber por las axilas, y se recomendaba que el colgamiento no durara más de una hora a pesar de que a veces este castigo se ejecutó durante más tiempo. Véase P.-F. Muyart De Vouglans, Les loix criminelles de France dans leur ordre naturel..., op. cit., p. 65.

${ }_{91}$ El carcan se ejecutaba llevando al condenado a pie detrás de la carreta del ejecutor de la pena, con las manos atadas por delante, y cuando llegaba a la plaza pública en la que estaba el poste el verdugo le ponía una argolla que estaba atada al poste por una cadena de hierro y era expuesto durante el tiempo establecido, poniendo un cartel delante de él y otro detrás en el que se escribía el delito que había cometido. Véanse D. Jousse, Traité de la justice criminelle de France, op. cit., pp. 60-61, y P.-F. MuYarT De VOuglans, Les loix criminelles de France dans leur ordre naturel..., op. cit., p. 66.

92 Como la pena de muerte por potence también era ejecutada en público, el condenado a presenciar esta ejecución a muerte se situaba en un lugar visible para el público que asistía a ver ejecutar la pena de muerte. Véanse D. Jousse, Traité de la justice criminelle de France, op. cit., pp. 45-46, y P.-F. Muyart De Vouglans, Les loix criminelles de France dans leur ordre naturel.., op. cit., p. 58. 
- Ser llevado por las calles con un sombrero de paja puesto ${ }^{93}$.

Esta forma de ejecución pretendía humillar al condenado, intimidar a los potenciales delincuentes y proclamar el monopolio penal del Estado ${ }^{94}$. En este catálogo de penas, todas las penas listadas eran penas infamantes de derecho. Las penas infamantes de derecho infamaban y deshonoraban con su imposición y ejecución. Si a eso se añade que la ejecución de estas ocho penas pretendía asegurar el deshonor mediante ejecuciones en público, se puede decir que estas ocho penas fueron las penas infamantes más graves de entre todas las existentes, porque su imposición y ejecución pretendía asegurar lo máximo posible causar deshonor, y porque la infamia ya era impuesta independientemente del tipo de ejecución que se efectuara.

\section{Ejecución infamante en privado}

Si una pena infamante no era ejecutada en lugares abiertos destinados a reunir al mayor número de personas posible, su ejecución se efectuaría en sede judicial sin mayor presencia que la de las partes de la causa judicial que había sido juzgada y sentenciada. Las penas infamantes ejecutadas en privado fueron las que aparecen a continuación:

- La pena de admonition ${ }^{95}$.

- Las défenses de reincidir ${ }^{96}$.

— La reparación de honor ${ }^{97}$.

93 Aunque Muyart de Vouglans no consideró que el paseo por las calles fuese una pena infamante, el mismo también describió la forma de ejecutar esta pena. Tanto Jousse como Muyart de Vouglans coincidieron en que la forma de ejecutar este paseo por las calles era paseando por las calles a la mujer condenada subida en un burro, sentada hacia atrás, llevando un sombrero de paja puesto y portando un letrero en el que podía leerse el ilícito que había cometido. Muyart de Vouglans recogió otros supuestos de hecho a los que se imponía otro tipo de paseos por las calles; se trataba en concreto por causas de bigamia y poligamia. Véanse D. Jousse, Traité de la justice criminelle de France, op. cit., p. 68, y P.-F. MuYART DE Vouglans, Les loix criminelles de France dans leur ordre naturel..., op. cit., pp. 65-66.

${ }_{94}$ M. Porret, «Atténuer le mal de l'infamie...», op. cit.

${ }^{95} \mathrm{La}$ admonition era una amonestación o reprimenda que hacía un juez de forma verbal en sede judicial a modo de advertencia sobre las consecuencias de reincidir, pronunciando exactamente la siguiente frase: «La Cour vous admoneste et vous fait grâce; soyez plus circonspect à l'avenir; retirez-vous; vous entendrez le reste de votre Arrêt». Véanse D. Jousse, Traité de la justice criminelle de France, op. cit., pp. 76-77, y P.-F. Muyart De Vouglans, Les loix criminelles de France dans leur ordre naturel..., op. cit., p. 80.

96 Podría entenderse que eran medidas cautelares impuestas al condenado para evitar que reincidiera. Véase D. Jousse, Traité de la justice criminelle de France, op. cit., p. 117.

${ }^{97} \mathrm{La}$ reparación honorable era una declaración del condenado ante el secretario judicial y ante el ofendido en la que afirmaba que consideraba que el ofendido era una persona honorable. En los casos en los que la injuria sufrida era grave, el ofendido tenía derecho a que 
- La injonction ${ }^{98}$.

- La pena de abstención de lugares ${ }^{99}$.

- La pena de interdicción temporal de oficios ${ }^{100}$.

- El plus amplement informé temporal ${ }^{101}$.

- El hors de Cour ${ }^{102}$.

- La multa en materia criminal ${ }^{103}$.

- La pena de azotes privada y sin marca ${ }^{104}$.

- Los intereses civiles.

- El bannissement temporal ${ }^{105}$.

dicha declaración se efectuara ante dos testigos de su elección, a que pidiera perdón y a que se levantara acta de esta declaración por un fedatario público, corriendo los gastos de todo esto a cuenta del ofensor. Véase D. Jousse, Traité de la justice criminelle de France, op. cit., p. 116.

${ }_{98} \mathrm{Ni}$ las fuentes de creación ni las fuentes de interpretación del Derecho definieron lo que se entendía por injonction. Sin embargo, de la poca información aportada al respecto por Jousse y Muyart de Vouglans en sus obras se puede deducir su significado. La injonction era una conminación judicial hecha a una persona para obligarla a actuar de una determinada manera ante el propio juez u otros empleados judiciales en determinados casos. Véanse D. Jousse, Traité de la justice criminelle de France, op. cit., p. 177, y P.-F. MuYarT De VOuGLANS, Les loix criminelles de France dans leur ordre naturel..., op. cit., p. 751.

${ }_{99} \mathrm{La}$ abstención de algunos lugares era una pena incurrida por vulneraciones de Derecho llevadas a cabo entre personas respetables que consistía en que el condenado a la misma no estuviera en el lugar de residencia del ofendido durante un plazo determinado. Véase D. Jousse, Traité de la justice criminelle de France, op. cit., pp. 78-79.

${ }^{100}$ Como su propio nombre indica, eran penas pronunciadas contra los titulares de oficios públicos en virtud de las cuales se les suspendía de empleo de forma temporal. Véanse D. Jousse, Traité de la justice criminelle de France, op. cit., p. 78, y P.-F. MuYART De VouGLANS, Les loix criminelles de France dans leur ordre naturel..., op. cit., p. 81.

${ }^{101}$ El plus amplement informé era una especie de medida cautelar que permitía condenar al imputado si aparecían más pruebas contra el mismo con el paso del tiempo. En este caso, la duración de esta pena sería por un tiempo determinado. Véanse D. Jousse, Traité de la justice criminelle de France, op. cit., pp. 83-84, y P.-F. MuYart De Vouglans, Les loix criminelles de France dans leur ordre naturel..., op. cit., pp. 78-79.

102 Esta pena era una medida que impedía que el condenado al plus amplement informé temporal pudiera reclamar daños y perjuicios al querellante en algunos casos. Véase P.-F. Muyart De Vouglans, Les loix criminelles de France dans leur ordre naturel..., op. cit., p. 79.

${ }^{103}$ La cuantía de ese tipo de multas era el fisco y estas multas eran condenas firmes en causa extraordinaria por haberse tratado de un ilícito público. Véanse D. Jousse, Traité de la justice criminelle de France, op. cit., p. 69, y P.-F. MuYART De Vouglans, Les loix criminelles de France dans leur ordre naturel..., op. cit., pp. 73 y 75.

${ }^{104}$ A diferencia de la pena de azotes sufrida públicamente e incluso a veces siendo marcado, la pena de azotes ejecutada en privado era infligida por el carcelero o torturador dentro de las dependencias de las cárceles y sin marcar al condenado a los azotes. Véanse D. Jousse, Traité de la justice criminelle de France, op. cit., p. 59, y P.-F. MuYart De Vouglans, Les loix criminelles de France dans leur ordre naturel..., op. cit., p. 63.

${ }_{105}$ El bannissement temporal consistía en abandonar durante un tiempo determinado el ámbito jurisdiccional en el que el juez que había condenado a esta pena era competente. 
- El bannissement perpetuo ${ }^{106}$.

- La aumône en materia civil ${ }^{107}$.

- La destitución, privación o interdicción perpetua de los oficios ${ }^{108}$.

- La degradación de nobleza ${ }^{109}$.

- Las galeras perpetuas ${ }^{110}$.

- Las galeras temporales ${ }^{111}$.

- La condena de la memoria ${ }^{112}$.

- El plus amplement informé indefinido ${ }^{113}$.

Véanse D. Jousse, Traité de la justice criminelle de France, op. cit., p. 65, y P.-F. MuYART De Vouglans, Les loix criminelles de France dans leur ordre naturel..., op. cit., pp. 69 y 72.

106 A diferencia del bannissement temporal, el perpetuo obligaba a abandonar el reino de forma definitiva. Véanse D. Jousse, Traité de la justice criminelle de France, op. cit., pp. 50-53, y P.-F. MuYart De Vouglans, Les loix criminelles de France dans leur ordre naturel..., op. cit., pp. 69 y 72.

${ }^{107}$ La aumône era un tipo de multa cuya cuantía iba destinada a obras pías y por ello no se ingresaba en las arcas públicas. Solamente sería infamante si imponía en una causa civil. Véase P.-F. Muyart De Vouglans, Les loix criminelles de France dans leur ordre naturel..., op. cit., pp. 76-77.

${ }^{108}$ En contraposición a las penas consistentes en interdicciones temporales, las perpetuas eran penas pronunciadas contra los titulares de oficios públicos en virtud de las cuales se les inhabilitaba para el desempeño del cargo público que ocupaban y a veces incluso para ocupar otro. Véanse D. Jousse, Traité de la justice criminelle de France, op. cit., pp. 73-74, y P.-F. MUYART De Vouglans, Les loix criminelles de France dans leur ordre naturel..., op. cit., p. 78.

109 Pena a través de la cual un noble era declarado plebeyo. A veces toda la descendencia del condenado también se veía afectada por esa declaración -incluidos los hijos que habían nacido antes del pronunciamiento de esta pena-. Véanse D. Jousse, Traité de la justice criminelle de France, op. cit., pp. 67-68, y P.-F. Muyart De Vouglans, Les loix criminelles de France dans leur ordre naturel..., op. cit., p. 77.

${ }_{110} \mathrm{Al}$ igual que las galeras temporales, ambas penas eran infamantes, aunque los efectos jurídicos de las galeras perpetuas eran más perjudiciales que los de las galeras temporales.

Antes de sufrir la pena de galeras, los condenados eran previamente azotados y marcados con las iniciales «GAL». Posteriormente se les llevaba a una prisión y permanecían en la misma hasta que se les destinaba en una galera. Mientras estaban en la prisión llevaban una argolla de hierro en el cuello con dos cadenas: una atada a la pierna y otra atada a uno de los brazos. Además de esas dos cadenas había otra cadena que unía a dos condenados a dicha pena. Cuando eran llevados a la galera correspondiente iban atados de dicha forma y una vez en la galera solamente se les quitaba la cadena que unía a los dos y se les ponía una nueva cadena que ataba a cada uno en su propio banco. Véase P.-F. Muyart De Vouglans, Les loix criminelles de France dans leur ordre naturel..., op. cit., pp. 56-58.

111 Ibid.

${ }_{112}$ La condena a la memoria consistió en dejar constancia de alguna forma del ilícito por el que un condenado a una pena capital había fallecido antes de que se ejecutara la misma. Véanse D. Jousse, Traité de la justice criminelle de France, op. cit., p. 55, y P.-F. MuYART DE Vouglans, Les loix criminelles de France dans leur ordre naturel..., op. cit., p. 76.

113 A diferencia del plus amplement informé temporal, el indefinido era una medida cautelar que permitiría condenar al imputado en cualquier momento si aparecían más pruebas contra el mismo. Véanse D. Jousse, Traité de la justice criminelle de France, op. cit., 
- La muerte civil $^{114}$.

- La privación de beneficios ${ }^{115}$.

- La privación de privilegios ${ }^{116}$.

- El desalojo de un bien inmueble.

- La supresión, lacerado o quema de escritos.

- La confiscación de los bienes del condenado.

Como puede verse, la gran mayoría de las penas infamantes eran ejecutadas en privado, pues todas las penas infamantes de hecho y unas treinta de las alrededor de cuarenta penas infamantes de derecho que hubo eran ejecutadas de esta forma. Dentro de este grupo hubo dos tipos de ejecución diferentes: 1) aquella que sobre todo pretendía infamar en mayor o menor medida ${ }^{117}$, y 2) aquella que sobre todo pretendía deshonorar al condenado a la misma ${ }^{118}$.

Siguiendo la clasificación que acaba de hacerse, el primer subgrupo sería el segundo grupo de penas infamantes más graves, solamente por

pp. 83-84, y P.-F. Muyart De Vouglans, Les loix criminelles de France dans leur ordre naturel..., op. cit., p. 78.

${ }_{114} \mathrm{La}$ condena a la muerte civil provocaba la pérdida de los bienes en beneficio del fisco o en beneficio de los herederos —esto último ocurría en aquellos lugares en los que la condena a la muerte civil no llevaba aparejada la confiscación de los bienes-. Sus efectos jurídicos eran los siguientes: incapacidad de testar, de suceder, de recibir donaciones, de denunciar, de prestar testimonio, de adquirir cualquier tipo de bien a excepción de pensiones y alimentos, y de contratar. Véanse D. Jousse, Traité de la justice criminelle de France, op. cit., pp. 85-86, y P.-F. MuYART De Vouglans, Les loix criminelles de France dans leur ordre naturel..., op. cit., p. 68.

$115 \mathrm{Al}$ igual que las privaciones e interdicciones perpetuas de oficios, las privaciones de beneficios eran penas pronunciadas contra los titulares de oficios públicos en virtud de las cuales se les inhabilitaba para el desempeño del cargo público que ocupaban y a veces incluso para ocupar otro. La única diferencia está en que el Derecho aplicable para este tipo de penas era el Derecho canónico y no el Derecho laico. Véase D. Jousse, Traité de la justice criminelle de France, op. cit., pp. 74-75.

116 Este castigo iba destinado a poblaciones en calidad de personas jurídicas, por lo que los privilegios que se perdían no eran de titularidad de persona física alguna. Véase D. JousSE, Traité de la justice criminelle de France, op. cit., p. 75.

${ }^{117}$ Las défenses de reincidir; la pena de abstención de lugares; la pena de interdicción temporal de oficios; el plus amplement informé temporal; el hors de Cour; la multa en materia criminal; la pena de azotes privada y sin marca; los intereses civiles; el bannissement temporal; el bannissement perpetuo; la aumône en materia civil; la destitución, privación o interdicción perpetua de los oficios; la degradación de nobleza; las galeras perpetuas; las galeras temporales; la condena de la memoria; el plus amplement informé indefinido; la muerte civil; la privación de beneficios; la privación de privilegios; el desalojo de un bien inmueble; la supresión, lacerado o quema de escritos, y la confiscación de bienes.

${ }_{118}$ Dentro de este grupo de penas estarían la admonition, la reparación honorable y la injonction. 
detrás de las penas infamantes ejecutadas en público. Ello venía motivado en que las penas infamantes de derecho que formaban parte del primer subgrupo deshonoraban y producían los efectos propios de la infamia, aunque el grado de deshonor que se pretendía producir con su ejecución era menor que en el de las penas infamantes ejecutadas en público. Por lo que se refiere a las penas infamantes de hecho que formaron parte del primer subgrupo, la ejecución de las mismas pretendía deshonorar tanto como las penas infamantes de derecho del mismo subgrupo, pero los efectos cuya ejecución provocaba no llegaban a la importancia y gravedad que tenían los de las penas infamantes de derecho. En cuanto al segundo subgrupo, el mismo solamente estuvo compuesto por penas infamantes de hecho y su forma de ejecución pretendió fundamentalmente deshonorar a los condenados, por lo que eran las penas infamantes más livianas de todas las que existieron.

\section{E) Efectos}

Ya indicamos que la principal característica de las penas infamantes en comparación con los otros tipos de penas era los efectos jurídicos perseguidos con su pronunciamiento y ejecución. Todas las penas tenían una finalidad principal y una finalidad secundaria, y ésta consistía en la irrogación de infamia, mientras que en el caso de las penas infamantes eran castigos cuyo único o al menos principal objetivo era infamar a los condenados a esas penas. En el Derecho francés del Antiguo Régimen nunca se estableció una escala de penas ${ }^{119}$, por lo que la doctrina graduó la gravedad de las penas existentes en el siguiente orden: las más graves eran las penas capitales, en segundo lugar estaban las penas corporales, a continuación estarían las penas aflictivas, en cuarto lugar aparecerían las penas infamantes y, por último, encontraríamos las penas pecuniarias. Esta clasificación demuestra que las penas más graves eran aquellas que atentaban contra la vida del condenado, después estarían aquellas que dañaban el cuerpo del condenado, a continuación vendrían las que limitaban la libertad, el cuarto tipo de penas más graves era aquel formado por los castigos que menoscababan el honor y las últimas penas en gravedad eran aquellas que hacían disminuir el patrimonio de los condenados. Como puede verse, el honor estaba estrechamente relacionado con las penas infamantes. Por tanto, las penas infa-

119 A. Laingui y A. Lebigre, Histoire du droit pénal. I le droit pénal, op. cit., p. 125. 
mantes ocuparon el cuarto lugar en el sistema punitivo configurado por la doctrina por dos razones: 1) porque el honor era el cuarto bien en importancia en el Derecho penal de aquella época, y 2) porque este tipo de penas solamente producían un efecto principal -al igual que las penas pecuniarias, siendo el efecto de éstas menor que el de las penas infamantes- frente a los dos efectos producidos por las demás sanciones penales.

En relación con los efectos jurídicos aparejados a las penas infamantes (de derecho), en ocasiones la normativa sí que indicó algunos de los efectos producidos por la imposición y ejecución de penas infamantes ${ }^{120}$. Sin embargo, una vez más la doctrina coetánea se ocupó de esta materia unificando en sus obras toda la teoría penal relacionada con los efectos anejos a la infamia.

La lectura conjunta de las fuentes normativas y doctrinales permite conocer que la infamia en que se incurría por el pronunciamiento y la ejecución de las penas infamantes (de derecho) producía los siguientes efectos:

- Incapacidad para poder seguir desempeñando las funciones de las dignidades y cargos públicos que se ostentaban o incapacidad para acceder a los mismos en el futuro ${ }^{121}$.

- Incapacidad para poder ser admitidos en las órdenes sagradas ${ }^{122}$.

- Limitación en muchos casos o incluso incapacidad para testificar en causas civiles y criminales ${ }^{123}$.

Además, la irrogación de infamia suponía quedar infame de forma perpetua $^{124}$.

Por su parte, la doctrina mayoritaria consideró que la infamia de hecho no producía efectos jurídicos ${ }^{125}$. Por este motivo interesa que nos centremos en el comentario y análisis de la infamia propiamente dicha.

${ }^{120}$ El mejor ejemplo de ello puede encontrarse en la Costumbre de Bretaña, puesto que esta normativa fue una de las que tenía mayor cantidad de disposiciones de Derecho penal. Éstas son las razones por las que se va a anotar en notas al pie el establecimiento de los efectos de la infamia en dicho cuerpo normativo.

121 Arts. 37 y 96 de la Costumbre de Bretaña, en Coutume de Bretagne, et usances particulières de quelques villes et territoires de la mesme province, 1. ${ }^{a}$ ed., Nantes, Nicolas Verger, 1725, p. 45; D. JOusse, Traité de la justice criminelle de France, op. cit., p. 114, y P.-F. MUYART De Vouglans, Les loix criminelles de France dans leur ordre naturel..., op. cit., p. 833.

122 D. Jousse, Traité de la justice criminelle de France, op. cit., p. 114.

${ }_{123}$ Art. 151 de la Costumbre de Bretaña, en Coutumes de Bretagne..., op. cit., p. 122; D. Jousse, Traité de la justice criminelle de France, op. cit., p. 114, y P.-F. MuYART DE Vouglans, Les loix criminelles de France dans leur ordre naturel..., op. cit., p. 833.

124 D. Jousse, Traité de la justice criminelle de France, op. cit., p. 115, y P.-F. MuYART DE Vouglans, Les loix criminelles de France dans leur ordre naturel..., op. cit., pp. 834-835.

${ }^{125}$ No opinó igual Loiseau, puesto que según el mismo la infamia de hecho cerraba la entrada a los cargos de la judicatura y a los cargos públicos de échevin, cónsul, administra- 
Los efectos de la infamia hacían referencia a situaciones profesionales o judiciales para las que su ejercicio requería unas cualidades morales ejemplares tanto por la importancia de la profesión o función a desempeñar como por las consecuencias que la conducta de esas personas podía ocasionar en otros.

Ya vimos que la infamia existió en el Derecho romano, y ya se indicó que el Derecho romano fue una de las fuentes del Derecho francés en aquella época. Esto podría suponer que los efectos establecidos para la infamia francesa fueran iguales o muy parecidos a los establecidos en el Derecho romano justinianeo y/o en el Derecho romano de la doctrina del Ius commune.

En época justinianea, la infamia producía como efectos jurídicos 1) la incapacidad para desempeñar las funciones de los cargos públicos y dignidades que se ocupaban y 2) la incapacidad para prestar testimonio en causas criminales. Lo mismo ocurrió con la duración de la infamia, porque en circunstancias normales la duración de los efectos de la misma era perpetua ${ }^{126}$. Si se atiende a lo establecido por la doctrina del Ius commu$n e$, el infame quedaba incapacitado para prestar testimonio, para desempeñar funciones para cuyo ejercicio se necesitaba tener especial relieve social o para desempeñar funciones que comprendían funciones de orden públi$\mathrm{co}^{127}$. En relación con la inadmisión en las órdenes sagradas, la doctrina canónica del Ius commune estableció como efecto jurídico de la infamia la exclusión de las órdenes sagradas ${ }^{128}$.

Los efectos jurídicos indicados para la infamia francesa procedían del Derecho existente en Francia desde la Baja Edad Media, mientras que el origen del primero de los efectos se remonta de forma casi inalterada desde la Alta Edad Media. La única diferencia destacable es que la doctrina canónica del Ius commune hizo referencia a las personas que ya formaban parte del ámbito eclesiástico, puesto que la infamia les impedía ascender e incluso mantener las dignidades eclesiásticas, mientras que la infamia francesa hacía referencia a los pretendientes a ocupar dignida-

dor de hospitales, incluso llegando a excluirlos de estos cargos en algunos casos. En cualquier caso, esta infamia no privaba al oficial de su oficio. Véase D. Jousse, Traité de la justice criminelle de France, op. cit., p. 114.

126 F. CAmacho DE Los Ríos, La infamia en el Derecho Romano, op. cit., pp. 88-89, 99-101 y 170-171, y A. MASFERRER, La pena de infamia en el Derecho bistórico español..., op. cit., pp. 56-58.

127 A. Masferrer, La pena de infamia en el Derecho bistórico español..., op. cit., pp. 99-100 y 102.

128 Ibid., pp. 114-115. 
des eclesiásticas ya que la infamia impedía que incluso se formara parte de esas instituciones. En cualquier caso, a rasgos generales se puede decir que queda demostrada la influencia de las fuentes romanas y canónicas de la Edad Media en los efectos jurídicos previstos para la infamia francesa por medio del Derecho romano justinianeo, el Derecho romano de la doctrina civil del Ius commune y el Derecho canónico de la doctrina canónica del Ius commune.

Donde no hubo continuismo entre el Derecho anterior y la infamia francesa del Antiguo Régimen fue en la cantidad de efectos aparejados a la infamia. En el Derecho romano justinianeo llegaron a haber hasta once principales efectos jurídicos diferentes ${ }^{129}$, la doctrina del Ius commune llegó a fijar cuatro efectos jurídicos principales para la infamia en el ámbito civil y cinco en el ámbito canónico ${ }^{130}$, y la infamia francesa solamente constó de

${ }^{129}$ Dichos efectos fueron los siguientes: 1) Incapacidad para prestar testimonio en juicios criminales. 2) Incapacidad para ser acusadores en juicios criminales. 3) Limitación de la capacidad para ejercer acciones populares, porque si el infame nombraba procurator y no se ejercitaba la exceptio, el magistrado no podría excluir de oficio a ese procurator, por lo que el infame podría litigar a través de aquél. 4) Incapacidad para ceder una acción. 5) Incapacidad para convertirse en magistrado, por lo que se trataba de una pérdida de la dignidad para llegar a ejercer funciones propias del cursus honorum. 6) Incapacidad para seguir disfrutando de los honores que se tenían, sobre todo de la dignitas de los cargos políticos de alta responsabilidad, por lo que se trataba de una pérdida de la dignidad para seguir ejerciendo funciones del cursus bonorum. Sin embargo, si esos honores hacían incurrir en grandes gastos a su titular, el infame no se exoneraría de esta obligación. 7) Incapacidad para postular en nombre de otro en un juicio salvo que pretendiera perseguir su propia injuria o por vindicar la muerte de un pariente suyo. En cualquier caso, el juez podía permitir que postulara independientemente de la causa judicial. 8) Separación de un orden o de la abogacía. 9) Incapacidad para realizar un testamento válido - como los hombres prostituidos-. 10) Legitimación de ejercitación de la inofficiosi actione contra testamentum por los hermanos desheredados en perjuicio del heredero infame o manchado levemente en su reputación. 11) Incapacidad de asumir el estado religioso por prostitutas y actrices. Véanse F. CAMACHo de los Ríos, La infamia en el Derecho Romano, op. cit., pp. 88-89, 99-101 y 170171, y A. MASFERRER, La pena de infamia en el Derecho histórico español..., op. cit., pp. 56-58.

${ }_{130}$ En esa época, los efectos aparejados a la infamia por la doctrina civil fueron los que se indican a continuación: 1) Incapacidad para acusar y prestar testimonio. La única excepción que existió a la incapacidad para acusar era promover un juicio por un crimen cometido contra su persona o allegados más próximos y en los delitos de lesa majestad. Por lo que respecta a la segunda incapacidad, si el juez autorizaba a que el infame prestara testimonio siendo torturado previamente podría prestar testimonio. En cualquier caso, cuando se tratara de tutelar intereses públicos de considerable relevancia las dos incapacidades dejaban de surtir efecto, en cuyo caso se torturaba antes. 2) Incapacidad de ser testigo en declaración testamentaria. En este sentido, tanto en la infamia de hecho como en la de derecho el heredero infame podía ver que el testamento que le instituía como heredero quedaba anulado por la querella inofficiosi testamenti presentada por los hermanos o hermanas consanguíneos. 3) Incapacidad para postular. Para los glosadores, la infamia podía ser summa infamia o infamia minor; en la primera están todos los crímenes que irrogaban infamia ipso iure y los 
tres efectos jurídicos. Aunque algunos de los efectos de las épocas anteriores podría haber estado agrupado en un solo efecto equiparable con los de la infamia francesa, se dio una clara reducción en el número de efectos aparejados a la infamia contraída en materia penal.

\section{CONCLUSIONES}

Durante el Antiguo Régimen, en Francia no hubo un sistema punitivo como tal debido fundamentalmente a la ausencia de fuentes normativas que determinasen de forma completa y sistemática todas las penas existentes. En este contexto, la doctrina jurídica no solamente comentó e interpretó el contenido del Derecho existente en las fuentes normativas, sino que tomó por base todas las fuentes del Derecho penal e impulsó el desarrollo de la teoría penal facilitando el conocimiento de todas las penas existentes y explicando su origen y finalidad.

$\mathrm{Al}$ ejercer esta labor la doctrina, la misma observó que el Derecho francés siempre se había ocupado y seguía ocupándose del honor tanto para protegerlo como para menoscabarlo a través de penas. Por otra parte, el Derecho romano había influenciado el contenido del Derecho todavía vigente en Francia, hasta el punto de que el Derecho romano fue una de las fuentes del Derecho penal hasta finales del Antiguo Régimen. Al apreciar que en Francia existían penas en virtud de las cuales se pretendía menoscabar exclusiva o principalmente el honor, el afán de la doctrina por explicar el origen y la finalidad de las penas les hizo buscar un nombre con el que denominar ese conjunto de penas. En el Derecho romano existía la institución de la infamia. Durante el Antiguo Régimen francés, la infamia siguió existiendo y el resultado que se producía con su pronunciamiento y ejecución seguía siendo dañar el honor de los condenados. Teniendo en cuenta todo esto, la doctrina observó que la infa-

perseguidos en juicio público. Dependiendo del tipo de infamia de que se tratara, esta limitación sería más o menos extensa. 4) Incapacidad para ser juez, abogado o asesor por tratarse de oficios que requerían «un grado mínimo de honor [...] de especial relieve social, o que comprenden funciones de orden público (munera publica)». Esto implicaba que los infames no pudieran recibir ni mantener oficios y cargos públicos.

Por lo que respecta a la doctrina canónica, los efectos fueron los que siguen: 1) Exclusión de las órdenes sagradas. 2) Incapacidad para poder seguir desempeñando las funciones de las dignidades, cargos eclesiásticos o beneficios que se ostentaban o para obtenerlos en el futuro. 3) Exclusión de la acusación. 4) Exclusión del testimonio. 5) Negación del derecho de apelación. Véase A. MASFERRER, La pena de infamia en el Derecho bistórico español..., op. cit., pp. 102-103 y 114-120. 
mia era una institución de Derecho romano utilizada incluso como pena y que comprehendía mejor que ninguna en su contenido el honor y la vulneración del mismo. Como en Francia hubo un conjunto de penas que en todo caso tenían por objetivo único o principal infamar a los condenados, la doctrina optó por elegir el nombre de «penas infamantes» para todos estos castigos. Siguiendo la distinción hecha sobre las penas infamantes entre penas infamantes de derecho y penas infamantes de hecho, la doctrina mayoritaria entendió que las penas infamantes (de derecho) del Antiguo Régimen francés eran aquellas en virtud de las cuales se infamaba a los condenados a las mismas además de menoscabar gravemente su honor. Como existieron numerosas penas cuya imposición y ejecución mancillaban el honor de los condenados pero sin infamarles, a este tipo de penas se les llamó «penas infamantes de hecho».

La ausencia de un sistema punitivo fijado de forma exhaustiva y unitaria por fuentes de creación del Derecho con una jerarquía clara y que estuvieran aplicadas en todo el territorio impidió que existiera un elenco completo y claro de penas consideradas infamantes. Por ello, una vez más las fuentes que trataron sobre esta materia fueron las diferentes obras doctrinales coetáneas. La única metodología a utilizar para poder redactar un catálogo de penas infamantes lo más completo posible era analizando todo lo escrito por la doctrina sobre la naturaleza de las diferentes penas, para a continuación elaborar un listado que aunara estas opiniones y observar si existieron penas unánimemente consideradas infamantes. En el listado obtenido a través de esa metodología, puede apreciarse que la opinión de la doctrina no fue unánime en cuanto a la consideración de las mismas penas como infamantes de derecho o de hecho. Por lo que respecta a las penas infamantes de derecho, ello se debió a que, a falta de una normativa clara al respecto, los argumentos proporcionados por las diferentes fuentes del Derecho en relación con alguna pena a veces se contradijeron o cambiaron con el paso del tiempo, por lo que a mayores contradicciones argumentativas sobre un castigo menos argumentos fueron sostenidos en favor de su carácter infamante. En cuanto a las penas infamantes de hecho, la amplitud de la definición de este tipo de penas permitió considerar que prácticamente todas las penas fueran infamantes de hecho; de ahí que solamente se pudieran listar las penas expresamente consideradas como infamantes de hecho siguiendo a un solo autor de la época.

Con el paso del tiempo, el número de penas que estuvieron en uso durante el Antiguo Régimen fue disminuyendo debido sobre todo al cam- 
bio de mentalidad de los juzgadores respecto a la dureza de los castigos a imponer. Independientemente del número de penas en uso a lo largo de este periodo, la presencia de las penas infamantes siempre fue igualmente importante tanto desde el punto de vista cuantitativo como cualitativo porque su vigencia y su uso apenas sufrieron modificaciones durante todo ese periodo; el número de penas infamantes de hecho no varió porque la noción del honor no sufrió variaciones significativas en ese periodo, y apenas cambió el número de penas infamantes de derecho porque los tipos de penas que más se vieron afectados en ese tendencia reduccionista del número de penas a imponer fueron las penas capitales, corporales y aflictivas al ser las penas más duras. En consecuencia, puede decirse que las penas infamantes siempre tuvieron un importante protagonismo en el Antiguo Régimen tanto por la cantidad de penas que la formaron como por la cantidad de casos en los que se imponían.

El estudio de la ejecución de las penas infamantes permitía conocer la forma a través de la que dichas penas irrogaban deshonor y/o infamia. Por su parte, el conocimiento de los efectos de las penas infamantes informaba sobre su verdadera razón de ser al dar a conocer la principal finalidad de este tipo de penas. Dependiendo de si la ejecución se efectuaba en público o en privado, los efectos de las penas infamantes serían más o menos graves, y con ello la ejecución y los efectos serían características estrechamente unidas cuyo tratamiento conjunto nos permitiría configurar un sistema punitivo de las penas infamantes que ninguna fuente del Derecho de aquella época estableció.

Por lo que respecta a la ejecución, todas las penas infamantes que se ejecutaban en público eran penas infamantes de derecho, así que este tipo de penas eran las penas infamantes más graves al asegurar el deshonor del condenado a través de la ejecución pública, añadiéndose a eso los efectos propios de la infamia inherente a esas penas. Entre las penas infamantes ejecutadas en privado, por el simple hecho de ejecutarse de esta forma el efecto deshonorante disminuía, por lo que conforme las penas infamantes tenían unos efectos menos parecidos a los de la infamia las mismas resultaban menos lesivas para el condenado y con ello menos graves. En cuanto a los efectos, los efectos inherentes a la infamia tuvieron un contenido muy similar al existente en las fuentes romanas y canónicas de la Edad Media al afectar a profesiones o cargos laicos y eclesiásticos con limitaciones de derechos muy similares. Siguiendo esta dinámica, las penas infamantes más graves eran las penas infamantes de derecho ejecutadas en público. A continuación estarían las penas infamantes de derecho ejecu- 
tadas en privado y cuya ejecución perseguía sobre todo aplicar las limitaciones propias de la infamia. En tercer lugar estarían las penas infamantes de hecho cuya ejecución tuviera el mismo funcionamiento que la ejecución de las penas infamantes de derecho anteriores - ejecutadas en privado y cuya ejecución persiguiera sobre todo aplicar los efectos jurídicos limitativos de la infamia, aunque dichas limitaciones no llegaran a tal nivel de gravedad-. Por último, las penas infamantes más livianas serían aquellas penas infamantes de hecho con cuya ejecución se perseguía sobre todo deshonrar.

\section{BIBLIOGRAFÍA}

Anchel, R., Crimes et châtiments au XVIIIe siècle, Paris, Livrairie académique Perrin, 1933.

BeIgnier, B., L'honneur et le droit, Paris, LGDJ, 1995.

Bourdot de Richebourg, C., Nouveau Coutumier Général, ou Corps des Coutumes générales et particulières de France, et des Provinces connues sous le nom des Gaules, parte II, t. II, Paris, Chez Michel Brunet, 1724.

Bruneau, A., Observations et maximes sur les matières criminelles, Paris, Chez Guillaume Cavelier, 1715.

Camacho de los Ríos, F., La infamia en el Derecho Romano, Alicante (Generalitat Valenciana), Conselleria de Cultura, Educació i Ciència-Instituto de Cultura «Juan Gil-Albert», 1997.

Carbasse, J.-M., Histoire du droit pénal et de la justice criminelle, Paris, Presses Universitaires de France, 2000.

— «Currant nudi: la répression de l'adultère dans le Midi médiéval (XIIe-Xve siècles)», en J. Poumarède y J.-P. Royer (eds.), Droit, histoire et séxualité, Lille, Publications de l'Espace juridique, 1987, pp. 83-102.

Castan, Y., «Exil ou prison en Languedoc au Xvine siècle», en J.-G. Petit (ed.), La prison, le bagne et l'histoire, Genève-Paris, Médecine et Hygiène-Les Méridiens, 1984, pp. 57-68.

Coutume de Bretagne, et usances particulières de quelques villes et territoires de la mesme province, 1. ' ed., Nantes, Nicolas Verger, 1725.

DAREAU, F., Traité des injures dans l'ordre judiciaire, ouvrage qui renferme particulièrement la jurisprudence du petit criminel, Paris, Prault, 1725.

Domat, J., Les loix civiles dans leur ordre naturel, t. I, La Haye, Adrien Moetjens, 1703.

FERnÁNDEZ DE BujÁN, A., «Observaciones acerca de las nociones de ignominia e infamia en Derecho romano», en Homenaje a Juan Berchmans Vallet de Goyti- 
solo, vol. IV, Madrid, Junta de decanos de los Colegios Notariales de España, Consejo General del Notariado, 1989, pp. 313-341.

Gouron, A., La science juridique française aux XIe et XIIe siècles: diffusion du droit de Justinien et influences canoniques jusqu'à Gratien, Milano, Giuffrè, 1978.

Halkin, L.-E., «La cruauté des supplices de l'Ancien Régime», Revue historique de droit français et étranger, Paris, Sirey, 1937, pp. 131-144.

- «Pour une histoire de l'honneur», Annales. Économies, Sociétés, Civilisations, cuarto año, núm. 4, 1949, pp. 433-444.

Jousse, D., Traité de la justice criminelle de France, t. I, Paris, Debure, 1771.

LAINGUI, A., «La sanction pénale dans le droit français du XVIIIe et XIXe siècle», en Recueil de la Société Jean Bodin pour l'bistoire comparative des institutions. La peine en Europe depuis le XviIIe siècle, vol. 57, Bruxelles, De Boeck Université, 1989, pp. 161-194.

— «Lois, juges et docteurs dans l'ancien droit pénal», Cabiers de philosophie politique et juridique, Caen, 1988, pp. 73-89.

Laingui, A., y Lebigre, A., Histoire du droit pénal. I le droit pénal, Paris, Cujas, 1979-1980.

- Histoire du droit pénal. II la procédure criminelle, Paris, Cujas, 1979-1980.

Loiseau, C., Cinq livres du droit des offices, Châteaudun, 1610.

LOISEL, A., Institutes coutumières ou manuel de plusieurs et diverses règles, sentences et proverbes, tant anciens que modernes, du Droit Coutumier et plus ordinaire de la France, Paris, Henry Le Gras, 1656.

LORRY, F., Code pénal, ou recueil des principales ordonnances, édits et déclarations, sur les crimes et délits, 2. ${ }^{a}$ ed., Paris, Desaint et Saillant, 1755.

MASFERRER, A., «Continuismo, reformismo y ruptura en la codificación penal francesa. Contribución al estudio de una controversia historiográfica actual de alcance europeo», Anuario de Historia del Derecho Español, t. LXXIII, 2003, pp. 407-424.

- La pena de infamia en el Derecho bistórico español. Contribución al estudio de la tradición penal europea en el marco del ius commune, Madrid, Dykinson, 2001.

Moeglin, J.-M., «Pénitence publique et amende honorable au Moyen Âge», Revue Historique, núm. 604, octubre-diciembre de 1997, pp. 225-269.

Muyart De Vouglans, P.-F., Les loix criminelles de France dans leur ordre naturel dédiées au Roi, Paris, Mérigot, Crapart y Benoît Morin, 1780.

Pommeray, L., Études sur l'infamie en droit romain, Paris, Sirey, 1937.

Porret, M., «Atténuer le mal de l'infamie: le réformisme conservateur de PierreFrançois Muyart de Vouglans», Crime, Histoire E Sociétés/Crime, History E Societies, vol. 4, núm. 2, 2000.

Rousseau de la Combe, G., Traité des matières criminelles suivant l'Ordonnance du mois d'Aôut de 1670, et les Édits, Déclarations du Roi, Arrêts et Réglemens intervenus jusqu'à présent, 5. 'ed., Paris, Théodore Le Gras, 1753. 
Juan B. Cañizares Navarro Las penas infamantes en las postrimerías del Antiguo...

SERPILLON, F., Code criminel, ou commentaire sur l'Ordonnance de 1670, parte I y II, Lyon, Frères Perisse, 1767.

Soulatges, J.-A., Traité des crimes, t. I, Toulouse, Antoine Birosse, 1762.

TimbaL, P.-C., «La confiscation dans le droit français des XIIIe et XIVe siècles», Revue bistorique de droit français et étranger, núm. 21, 1943, pp. 44-79. 